\title{
环戊并二噻吩衍生物的合成及其应用
}

\author{
胡金明钟春晓李晓艳贾雄魏颖* 解令海*
}

(南京邮电大学信息材料与纳米技术研究院 省部共建有机电子与信息显示国家重点实验室

分子系统与有机器件研究中心 南京 210023)

\begin{abstract}
摘要 环戊并二噻吩衍生物作为一类具有刚性平面的类芴骨架结构的分子, 其光电材料衍生物由于具有带隙低、电导 率高和良好的电荷传输性能等优点在塑料电子领域有着广泛的应用. 同时由于其易于进行结构修饰，能够方便、快捷 地引入各种功能基团，可拓展合成多种衍生物. 依据环戊并二噻吩上噻吩 $\mathrm{S}$ 原子的位置不同，可以将其分为 6 种构造 异构体. 在这些构造异构体中, 目前关于 $4 H$-环戊 $[2,1-b: 3,4-b]$ 二噻吩衍生物的研究报道较多. 作者对 $4 H$-环戊 $[2,1-b: 3,4-b]$ 二噻吩衍生物的合成、性质及其在有机太阳能电池(OSCs)、有机场效应晶体管(OFETs)、有机发光二极管 (OLEDs)等领域的研究进展进行了全面综述, 并对其有机半导体的格子化学进行了展望.
\end{abstract}

关键词 环戊并二噻吩; $\pi$-系统; 类芴; 有机太阳能电池; 有机场效应晶体管

\section{Synthesis and Application of Cyclopentadithiophene Derivatives}
Xinming $\mathrm{Hu}$
Chunxiao Zhong
Xiaoyan Li
Xiong Jia
Ying Wei*
Linghai Xie*
(Centre for Molecular Systems and Organic Devices (CMSOD), State Key Laboratory of Organic Electronics and Information Displays \& Institute of Advanced Materials (IAM), Nanjing University of Posts \& Telecommunications, Nanjing 210023, China)

\begin{abstract}
Cyclopentadithiophene (CPDT) derivatives, as a class of fluorene-like molecular building blocks that have a wide range of applications in the design of organic optoelectronic materials due to their easily molecular tailoring, electron-rich, low band gap, high electrical conductivity and good charge transport properties in the field of plastic electronics. At the same time, cyclopentadithiophene is easy to carry out structural modification, which can introduce various functional groups conveniently and quickly, and can expand a variety of derivatives. Cyclopentadithiophene can be divided into six structural isomers based on the position of the $\mathrm{S}$ atom on thiophene. Among these structural isomers, there are many reports on $4 H$-cyclopenta[2,1-b:3,4- $b$ ]dithiophene derivatives. In this article, we review mainly the synthesis and properties of $4 H$-cyclopenta[2,1-b:3,4- $b$ ]dithiophene derivatives and applications in organic solar cells (OSCs), organic field-effect transistors (OFETs). The research progress in organic light-emitting diodes (OLEDs) and other fields is also comprehensively summarized. The perspectives of the gridochemistry of CPDT-based organic semiconductors will be made finally.
\end{abstract}

Keywords cyclopentadithiophene; $\pi$-system; fluorene-like; organic photovoltaic; organic field effect transistor

\section{1 引言}

环戍并二噻吩类衍生物作为一类刚性平面的类芴 联噻吩结构 ${ }^{[1]}$, 相当于芴分子中与亚甲基碳桥相连的 “两个联苯环” 被 “两个噻吩环” 替代而形成, 其具有窄 的带隙、较高的电导率和强的分子间相互作用等优异特 性 ${ }^{[2-3]}$, 在有机太阳能电池 ${ }^{[4-5]}$ 、有机场效应晶体管 ${ }^{[6]}$ 、有 机发光二极管 ${ }^{[7]}$ 、超级电容器 ${ }^{[8-9]}$ 等领域有着非常重要且 广泛的应用. 依据环戊并二噻吩类衍生物噻吩上的 $\mathrm{S}$ 原 子的位置不同, 可以将其分为 7H-环戊 [1,2- $b: 4,3-b]$ 二噻 吩(1)、4H-环戊[2,1- $b: 3,4-b]$ 二噻吩(CPDT) (2)、7H-环戊 $[1,2-b: 3,4-b]$ 二噻吩 $(3) 、 7 H$-环戊 $[1,2-c: 3,4-c]$ 二噻吩(4)、
$4 H$-环戊 $[2,1-b: 3,4-c$ 二 噻吩(5)、7H-环戊 $[1,2-b: 3,4-c$ 二

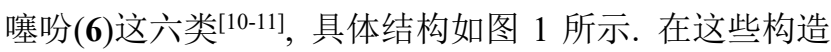
异构体中, 目前关于 CPDT 及其衍生物的研究报道较多, CPDT 可以作为分子模块在其桥接碳(4 号位, 图 1)处进 行官能化, 可以引入各种取代基 ${ }^{[12]}$ (例如氧化还原活性 部分、烷基链等), 这些优良的单体性质及可控官能团化 使得其在光电材料中的应用更加突出 ${ }^{[13]}$. 目前 CPDT 及 其衍生物的发展很迅速, 对其研究报道也很多, 结合我 们课题组的研究工作，本文将对 CPDT 及其衍生物的合 成研究发展和其在有机太阳能电池、有机场效应晶体管 等实际应用领域进行全面综述，且重点介绍了 CPDT 及 其衍生物在有机太阳能电池方面的研究与应用.

*E-mail: iamywei@njupt.edu.cn; iamlhxie@njupt.edu.cn

Received May 7, 2021; published June 10, 2021.

Project supported by the National Natural Science Foundation of China (Nos. 21774061, 22071112) and the Natural Science Research Project of Universities in Jiangsu Province (No. 20KJB150038).

项目受国家自然科学基金(Nos. 21774061, 22071112)和江苏省高校自然科学研究面上项目(No. 20KJB150038)资助. 

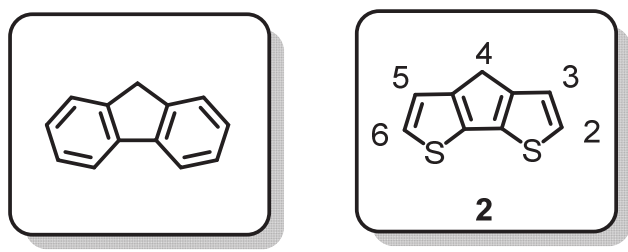

图 1 环戊并二噻吩的六类构造异构体

Figure 1 Six structural isomers of cyclopentadithiophene

\section{CPDT 及其衍生物的合成方法}

CPDT 的合成方法主要有卤素-锂交换反应(路线 a)、 肼还原反应(路线 $b$ )、分子内傅克反应(路线 $\mathrm{c}$ )、乌尔曼 偶联反应(路线 $\mathrm{d}$ )等, 四种具体反应路线如图 2 所示. 1968 年 Kraak 课题组 ${ }^{[11]}$ 首次提出卤素-锂交换反应合成 CPDT, 利用 3,3'-二噻吩基甲醇作为原料, 在氢化铝锂 和三氯化铝作用下得到 3,3'-二噻吩甲烷, 随后在液溴的 条件下溴化得到 2,2'二溴取代衍生物, 紧接着通过正丁 基锂进行金属卤素交换, 最后在氯化铜催化下, 经过分 子内氧化偶联反应, 以 $15.4 \%$ 的产率得到产物 CPDT(图 2a). 在接下来的几年里研究者们对 CPDT 合成方法和 纯化步骤进一步优化, 但是其产率仍然很低. 直到 2002 年, Turner 课题组 ${ }^{[14]}$ 报道了一种肼还原方法, 该方法直 接将 $4 H$-环戊 $[1,2-b: 5,4-b]$ 二噻吩-4-酮(CDT)还原成

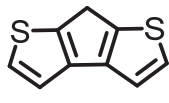

1

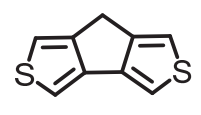

4

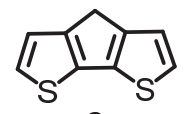

2

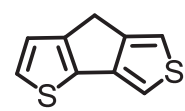

5

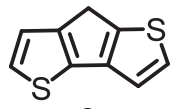

3

6

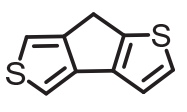

CPDT, 产率达到了 $62 \%$ (图 2b). 虽然该方法能够较高产 率合成 CPDT, 但是其中使用的肼是剧毒物质，对人体 有伤害且不环保, 因此发展绿色制备方法是非常有必要 的. 2010 年, Mierloo 课题组 ${ }^{[15]}$ 便报道了一种绿色环保、 方便有效的分子内傅克反应，合成了一系列官能团化的 CPDT(图 2c), 该方法可以同时实现对称和不对称官能 化的 CPDT. 2017 年, Zhao 等 ${ }^{[16-18]}$ 在总结前人合成方法 的基础上, 发展了一种目前使用最广泛的合成 CPDT 的 路线, 该路线是首先在正丁基锂作用下 3-澳噻吩锂化得 到 3-噻吩锂化物, 随后与 3-甲醛噻吩反应得到二(噻吩3-基)甲醇, 然后在氢化铝锂和三氯化铝作用下还原得 到双(噻吩-3-基)甲烷, 之后在 $N$-碘代琥珀酰胺的作用下 得到双(2-碘噻吩-3-基)甲烷，最后在铜(I)的作用下通过 乌尔曼偶联反应以 $60 \%$ 的产率得到产物 CPDT(图 2d).

a 卤素-锂交换反应

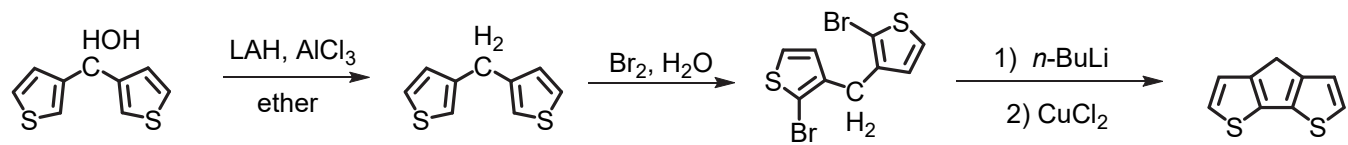

$\mathrm{b}$ 肼还原反应

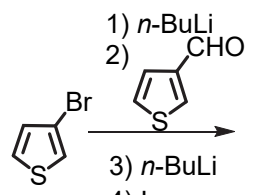

4) $I_{2}$

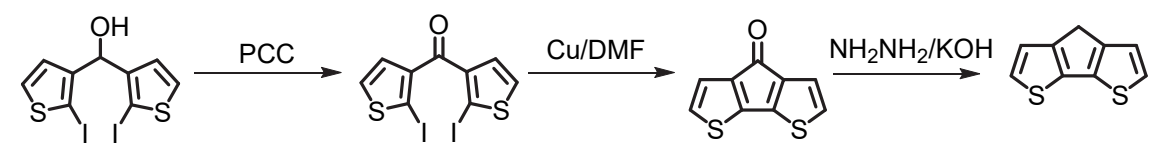

C 分子内傅克反应

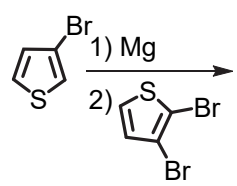<smiles>Brc1ccsc1-c1cccs1</smiles>

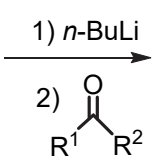<smiles>[R]C([R])([R])c1ccsc1-c1cccs1</smiles><smiles>[R]C1([R])c2ccsc2-c2sccc21</smiles>

$\mathrm{Pd}(\mathrm{dppf}) \mathrm{Cl}_{2}$

$\mathrm{R}^{1}=\mathrm{R}^{2}=\mathrm{Et}$, Cy, Pentyl, Octyl, Isobutyl; $\mathrm{R}^{1}=\mathrm{Me}, \mathrm{R}^{2}=$ Nonyl; $\mathrm{R}^{1}=$ Octyl, $\mathrm{R}^{2}=2$-Ethylhexyl $\mathrm{d}$ 乌尔曼偶联反应
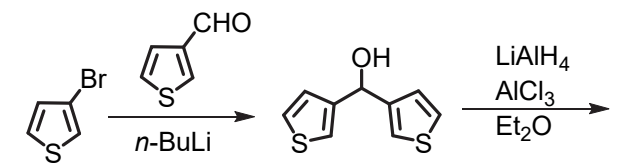<smiles>O=C1CCC(=O)N1I</smiles><smiles>Ic1sccc1Cc1ccsc1I</smiles><smiles></smiles>

图 2 CPDTs 的四种合成方法

Figure 2 Four synthetic methods of CPDTs 
此外 CPDT 的 2 号位、4 号位和 6 号位具有高的反 应活性，所以可进行选择性修饰引入各种基团，构筑系 列 CPDT 类小分子、寡聚物、共聚物、均聚物和支化聚 合物 ${ }^{[2,19-22]}$ (图 3). 在 CPDT 的 4 号位可以引入羰基 ${ }^{[23]}$ 、 芳基和烷基等功能基团. 其中引入羰基的 CDT, 与芴酮 相似，可以通过镍催化的格氏-伍尔兹交叉偶联反应 ${ }^{[24]}$ 从而得到系列螺环三维小分子[25-26], 应用于小分子受体 等领域中. 此外, 还可以利用 Knoevenagel 缩合和格氏 反应等对 CDT 进行选择性官能团修饰, 获得系列小分 子, 如环戍并二噻吩基叔醇、缩醛、芳基化合物和烯烃 等衍生物. 在这里, 环戊二噻吩基叔醇作为 A1B2 型合 成子，在酸性条件下，可以发生傅克聚合得到一类新型 的支化聚合物 ${ }^{[21]}$. 同样在 CPDT 的 2 号位和 6 号位可以 通过 Stille 偶联反应聚合得到一系列聚合物. 其中 CPDT 单元及其衍生物是目前应用最为成功的窄带隙供体单 元(D), 与吸电子单元(A) 2,1,3-苯并噻二唑(BTH)等所形 成的 D-A 型聚合物 ${ }^{[27]}$ 等明星分子在太阳能电池中得到 了广泛运用, 可以通过对 “ $\mathrm{D}$ ”与 “ $\mathrm{A}$ ” 单元的单体修饰, 或者改变 “ $\mathrm{A}$ ” 单元等策略进行聚合物结构的优化, 也 为该领域提供了更加优越的分子选择.

\section{CPDT 衍生物的物理化学性质和光电性质}

CPDT 在紫外吸收光谱中最大吸收较 2,2-联噻吩 $\left(\lambda_{\max }=302 \mathrm{~nm}\right)$ 发生红移 $\left(\lambda_{\max }=312 \mathrm{~nm}\right)$, 表明 CPDT 在 结构上具有较大的共轭体系, 同时 CDT 在紫外吸收光 谱中最大吸收为 $474 \mathrm{~nm}$, 其共轭程度在该系列 CPDT 单 体分子中最高 ${ }^{[28]}$. 此外, CPDT 的单体聚合物具有较高
的电导率 $\left(\sigma=40 \mathrm{~S} \cdot \mathrm{cm}^{-1}\right)$, 其氧化还原电极分别为 $+0.59 \mathrm{~V}$ 和 $-0.99 \mathrm{~V}$ (饱和甘录电极 (SCE) 作为参比电 极), 根据经验公式可以算出 HOMO 和 LOMO 能级分别 为 $-0.98 \mathrm{eV}$ 和 $0.60 \mathrm{eV}$, 带隙为 $1.58 \mathrm{eV}$ ，属于窄带隙聚 合物 ${ }^{[29-30]}$. 基于 CPDT 单元的系列聚合物 ${ }^{[31-36]}$ (表 1, 图 4), 带隙均在 $1.50 \mathrm{eV}$ 左右, 都是非常良好的窄带隙聚合 物材料. 事实上, $\pi$-共轭阻断连接可以有效抑制带隙减 小, 从而保持较宽的带隙 ${ }^{[21]}$. 最为重要的是, 由于 CPDT 类材料属于富电子基团，导致容易被氧化，进而 影响材料与器件稳定性. 因此通过分子结构设计来探索 结构稳定的 CPDT 是重要的研究思路. 最近, 我们在有 机半导体的空间设计基础上，提出了格子化策略设计. 在 CPDT 结构中, 通过理论研究类芴结构 CPDT 基的风 车格 ${ }^{[36]}$ (WG-CPDT)(图 4)表现出降低的重组能, 四元 CPDT 风车格的带隙均在 $3.0 \mathrm{eV}$ 以上. 风车格属于格芳 烃，格芳烃是一类不同于大环化合物的环状化合 物 ${ }^{[37-38]}$, 其具有棱角分明的结构骨架、可延伸拓展、可 安装以及可程序化移植等能力，受启于中国方圆文化与 古代窗格智慧，我们将构筑格芳烃的方法称为格子化. 目前我们已经设计并合成出五类芴基格芳烃，分别为:

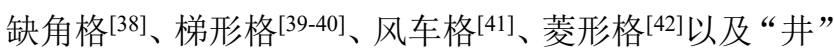
字形格 ${ }^{[43]}$. 基于此, 我们开始向类芴结构拓展, CPDT 作 为类芴结构将成为格子化的关键构筑合成子单元，可以 构建系列 CPDT 基格芳烃. 目前的 CPDT 类衍生物更多 是趋向于窄带隙化合物的研究，在光电材料领域有着非 常重要的地位，格子化效应正在探索中，未来 CPDT 基 的五类格芳烃将为 OPV 材料设计提供新的思路.

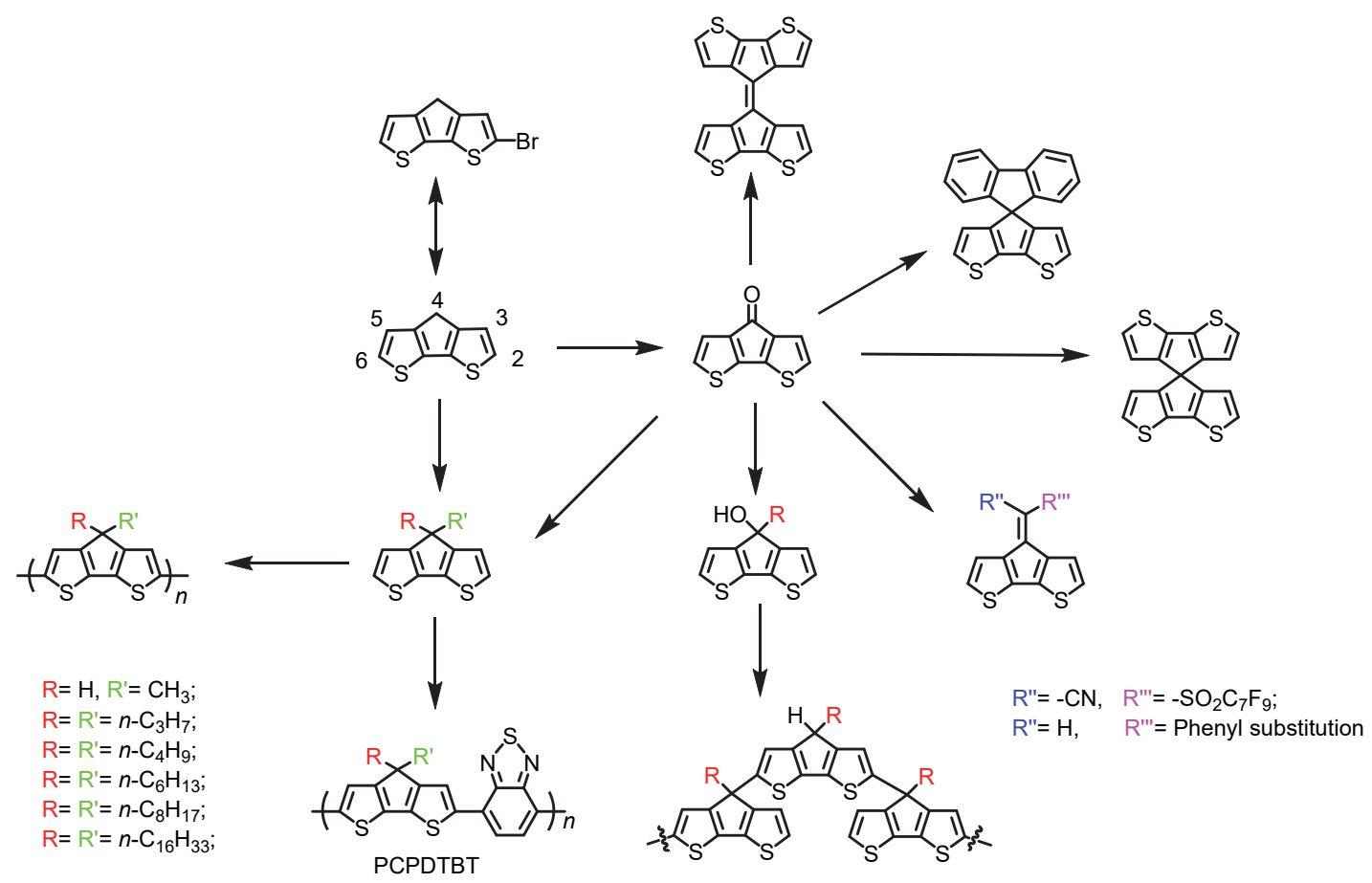

图 $3 \mathrm{CPDT}$ 衍生物的分子结构

Figure 3 Molecular structure of CPDT derivatives 
表 1 CPDT 衍生物的光物理数据、能级和带隙

Table 1 Photophysical data, energy levels, and band gaps of CPDT derivatives

\begin{tabular}{|c|c|c|c|c|c|}
\hline & \multirow{2}{*}{$\begin{array}{l}\text { Solution } \\
\lambda_{\max } / \mathrm{nm}\end{array}$} & \multirow{2}{*}{$\begin{array}{c}\text { Film } \\
\lambda_{\max } / \mathrm{nm}\end{array}$} & \multicolumn{3}{|c|}{ Cyclic Voltammetry } \\
\hline & & & $\mathrm{HOMO} / \mathrm{eV}$ & $\mathrm{LOMO} / \mathrm{eV}$ & Band-gap/eV \\
\hline EH-DFBT & 712 & 761 & -5.16 & -3.57 & 1.59 \\
\hline PehCDT-BT & 546 & 546 & -5.20 & -3.44 & 1.76 \\
\hline BDTCPDT & 776 & 779 & -5.18 & -3.31 & 1.87 \\
\hline PCPDTBTNT & 613 & 616 & -5.04 & -3.53 & 1.51 \\
\hline UF-C2C5-2F & 750 & - & -5.46 & -4.07 & 1.39 \\
\hline $\mathrm{C} 1-1-\mathrm{C}_{2} \mathrm{H}$ & - & - & -5.07 & -1.84 & 3.23 \\
\hline C1-1-F & - & - & -5.05 & -1.55 & 3.50 \\
\hline $\mathrm{C} 1-1-\mathrm{CH}_{3}$ & - & - & -4.78 & -1.30 & 3.48 \\
\hline
\end{tabular}

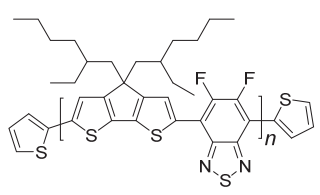

EH-DFBT

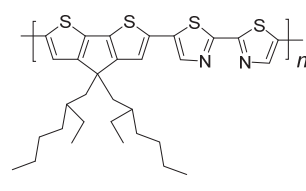

PehCDT-BT

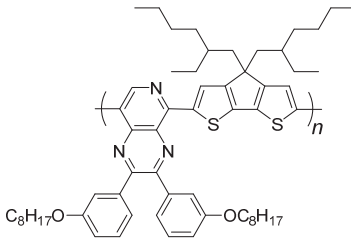

BDTCPDT

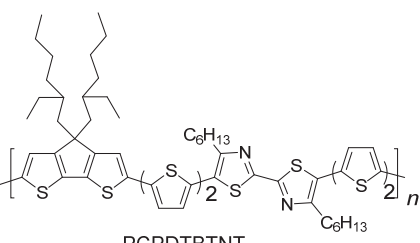

PCPDTBTNT

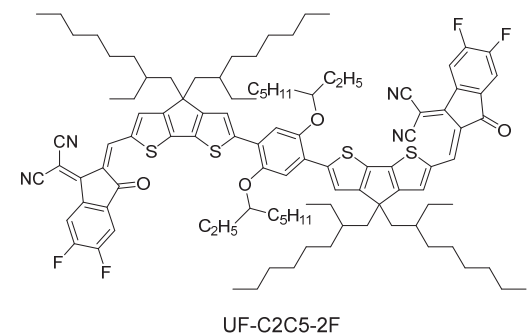

UF-C2C5-2F

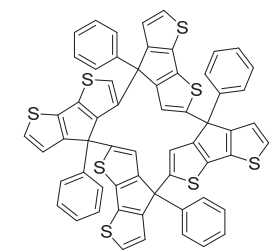

WG-CPDT

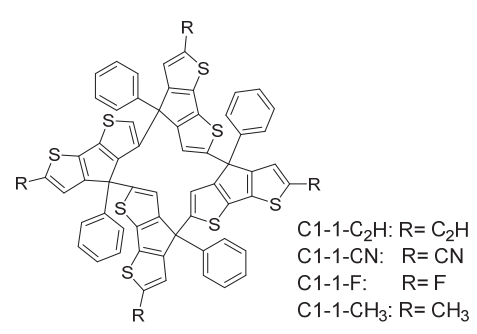

图 $4 \mathrm{CPDT}$ 衍生物的分子结构

Figure 4 Molecular structures of CPDT derivatives

\section{CPDT 类半导体在塑料电子领域中的应用}

\section{1 在有机太阳能电池中的应用}

\subsubsection{CPDT 在富勒烯太阳能电池中的应用}

太阳能电池包含的种类十分丰富, 其中具有成本 低、重量轻、柔性好和易于大面积制备等独特的优点的 聚合物太阳能电池成为近年来科学家研究的热点 ${ }^{[44]}$. 到了 1992 年由 Heeger 课题组发现了共轭聚合物和富勒 烯之间存在超快的电荷转移 ${ }^{[45-46]}$, 并且在 1995 年实现 了由溶液制备的聚合物/富勒烯衍生物 $\mathrm{PC}_{61} \mathrm{BM}$ 体异质 结太阳能电池 ${ }^{[47]}$, 在这之后聚合物/富勒烯太阳能电池 就得到了广泛的研究 ${ }^{[48]}$. 直到 2007 年, Heeger 课题组 ${ }^{[20]}$ 研究了新型窄带隙共轭聚合物 PCPDTBT(图 5)的光学和 电荷传输性质, 实现了 CPDT 衍生物在聚合物/富勒烯 太阳能电池中的应用。研究结果表明, 在基于 PCPDTBT:PC ${ }_{61} \mathrm{BM}$ (图 5) 的太阳能器件中所获得的参数 结果与众所周知的基于 $\mathrm{P} 3 \mathrm{HT}$ (图 5): $\mathrm{PC}_{61} \mathrm{BM}$ 的太阳能器 件获得的结果相似, 特别是基于 PCPDTBT:PC ${ }_{61} \mathrm{BM}$ 混 合材料的器件光响应性比原始 PCPDTBT 高约 100 倍. 另外, 当 PCPDTBT 用作 PCPDTBT: $\mathrm{PC}_{61} \mathrm{BM}$ 本体异质结
器件的有源组件时，可通过改善太阳光收集来实现聚合 物光伏中高功率转换效率. 在接下来的研究工作中, CPDT 衍生物在结构、供体、溶解度等方面的研究探索 得到了一系列富勒烯太阳能电池, 并取得了较好的器件 性能.

2008 年 Scherf 课题组 ${ }^{[27]}$ 研究合成了两种新型基于 CPDT 的结构, 通过在供体 CPDT 和受体 BTH 间引入噻 吩基团以及在受体 $\mathrm{BT}$ 上进行结构微调的方式合成了窄 带隙聚噻吩聚合物 PCPDTTBTT 和 PCPDTQ(图 5), 研 究结果发现当 PCPDTTBTT/PC ${ }_{61} \mathrm{BM}$ 混合物所组成的富 勒烯太阳能电池的吸收波长范围超过 $800 \mathrm{~nm}$ 同时可获 得 $2.1 \%$ 的光电转换效率(PCE).

2009 年 Janssen 课题组 ${ }^{[17]}$ 以 CPDT 为基础, 通过改 变受体及增加烷基链的方式制备了 5 种不同的缺电子、 带隙降低的芳烃单元的交替共聚物 PCPDT-Q、 PCPDT-BO、PCPDT-BT、PCPDT-BBT 和 PCPDT-TP(图 $5)$. 其中以苯并噁二唑(BO)或 BTT 为缺电子单元的聚合 物制备的富勒烯太阳能电池性能最好, 与 $\mathrm{PC}_{61} \mathrm{BM}$ 混合 后, 所获得的器件开路电压 $\left(V_{\mathrm{OC}}\right)$ 明显高于基于 PCPDT-BT:PC ${ }_{61} \mathrm{BM}$ 的混合器件. 最佳器件为基于 
PCPDT-BO: $\mathrm{PC}_{61} \mathrm{BM}$ 共混所制备的器件, 其短路电流 $\left(J_{\mathrm{SC}}\right)$ 为 $5.4 \mathrm{~mA} \cdot \mathrm{cm}^{-2}$, 填充因子 $(F F)$ 为 $60 \%, V_{\mathrm{OC}}$ 为 0.78 $\mathrm{V}$, 在最佳光学带隙为 $1.47 \mathrm{eV}$ 时, 得到最大 PCE 超过 $2.5 \%$. 同时从带隙 $\left(E_{\mathrm{g}}\right.$ ) 到 $\mathrm{e} V_{\mathrm{OC}}$ (基本电荷与开路电压的 积)的能量损失为 $0.69 \mathrm{~V}$, 接近 $0.6 \mathrm{~V}$ 的预期最小损失, 是聚合物/富勒烯太阳能电池报告的最低值之一.

2009 年, Lin 课题组 ${ }^{[32]}$ 合成了 CPDT-BT 基共聚物 $\mathrm{P} 1 \sim \mathrm{P} 6$ 六个共聚分子(如图 5). 这些共聚物具有从紫外 到近红外(400 $800 \mathrm{~nm}$ )的宽吸收范围, 1.70 $1.94 \mathrm{eV}$ 的 窄光学带隙, 同时表现出优异的电荷传输性能和良好的 可加工性, 它们的空穴迁移率在 $3.3 \times 10^{-4} \sim 5.6 \times 10^{-4}$ $\mathrm{cm}^{2} \cdot \mathrm{V}^{-1} \cdot \mathrm{s}^{-1}$ 的范围内. 其中 $\mathrm{P} 4$ 分子与 $\mathrm{PC}_{61} \mathrm{BM}$ 混合后得 到的聚合物太阳能电池器件, 显示出了最佳的器件性 能, 其 $J_{\mathrm{SC}}$ 为 $8.00 \mathrm{~mA} \cdot \mathrm{cm}^{-2}, V_{\mathrm{OC}}$ 为 $0.70 \mathrm{~V}, F F$ 为 $53.7 \%$, PCE 为 $3.04 \%$. 这些共聚物的研究发现展示了一个新的 共轭共聚物家族, 为低成本的聚合物/富勒烯太阳能电 池应用与研究提供了方向, 同时也有课题组通过改变交 替单元、烷基链策略、D-A 单元的比例掺杂等方面研究 CPDT 衍生物在富勒烯太阳能电池中的应用.

2010 年 Wei 课题组 ${ }^{[33]}$ 又制备了系列基于受体吡啶 并 $[3,4-b]$ 吡嗪(PP)单元, 与供体苯并 $[1,2-b: 3,4-b$ 二 噻吩 (BDT) 单元或 CPDT 单元共轭的窄带隙共聚物 P7 P10(图 5). 通过两种不同的供体调节聚合物的吸收光 谱、带隙和能级, 其表现出了不同的给电子能力. 其中 CPDT 单元比 BDT 单元具有更高的供电子能力, 与 PP 受体共轭时, CPDT 单元的存在会导致更强的分子内电 荷转移(ICT)的相互作用. 由于噻吩/联噻吩在其聚合物 主链中的存在, 该系列聚合物覆盖了从可见光到近红外 的太阳光吸收, 同时在含有 CPDT 的聚合物光谱吸收相 对于含有 $\mathrm{BDT}$ 的聚合物显著红移. 结果表明当使用 $\mathrm{P} 10: \mathrm{PC}_{71} \mathrm{BM}$ (图 5)共混制备器件时, 可以获得最均匀的 器件薄膜表面, 有助于更有效的载流子传输, 也获得了 最佳的富勒烯太阳能电池性能, 其 $J_{\mathrm{SC}}$ 为 10.85 $\mathrm{mA} \cdot \mathrm{cm}^{-2}, \mathrm{PCE}$ 为 $3.15 \%$. 表明了 $\mathrm{CPDT}$ 单元比 BDT 单 元更适合应用于富勒烯太阳能电池中. 同年 Ding 课题 组 ${ }^{[49]}$ 也设计并合成了一种基于四嗪的窄带隙半导体聚 合物 PCPDTTTz(图 5). 这是第一个以四嗪为主链的可 溶液加工的共轭聚合物, 该聚合物显示出良好的热稳定 性和宽吸收范围(450 700 nm). HOMO 和 LUMO 能级 为 $-5.34 \mathrm{eV}$ 和 $-3.48 \mathrm{eV}$, 电化学带隙为 $1.86 \mathrm{eV}$. 同时 基于 PCPDTTTz:PC ${ }_{71} \mathrm{BM}$ 的富勒烯太阳能电池的 PCE 为 $5.4 \%$.

2010 年, Shim 课题组 ${ }^{[34]}$ 将富电子的 CPDT 单元和缺 电子的噻唑(BT)或噻唑并噻唑( $\mathrm{TZ}$ )单元交替掺入主骨 架合成基于 CPDT 的窄带隙共聚物 PehCDT-BT、 PehCDT-TZ、PocCDT-BT 和 PocCDT-TZ(图 5). 这四种 聚合物显示出宽的吸收范围(300 $800 \mathrm{~nm})$, 光学带隙 为 $1.58 \sim 1.81 \mathrm{eV}$, 其中 PehCDT-TZ 表现出最佳的光伏 性能, 与 PCBM 混合时, 在 AM 1.5 光谱(即地面中午晴
空太阳光, $1.000 \mathrm{~kW} \cdot \mathrm{m}^{-2}$ )作为测试电池效率的标准光 源，PehCDT-TZ 表现出最佳的光伏性能， $V_{\mathrm{OC}}$ 为 $0.69 \mathrm{~V}$, $J_{\mathrm{SC}}$ 为 $7.14 \mathrm{~mA} \cdot \mathrm{cm}^{-2}, \mathrm{PCE}$ 为 $2.23 \%$.

2012 年 Maes 课题组 [50] 合成了共聚物 PCPDT-DTTzTz(图 5)并研究 CPDT 的 4 号位的(烷基)官 能化模式和材料纯度对窄带隙聚合物材料光伏性能的 影响. 研究发现, 这些取代基的添加不仅改善了溶解度, 而且诱导了聚合物的堆积趋势，从而形成了半结晶材 料. 当 PCPDT-DTTzTz 与 $\mathrm{PC}_{71} \mathrm{BM}$ 混合并集成到富勒烯 太阳能电池中时, 在 $\mathrm{AM} 1.5$ 光谱作为测试电池效率的 标准光源, 其 PCE 为 $2.43 \%$. 随后通过尺寸排阻色谱法 纯化该共聚物后, 器件的 PCE 显著提高至 $4.03 \%$, 纯化 后的聚合物表现出相对较高的场效应载流子迁移率，达 到了 $1.0 \times 10^{-3} \mathrm{~cm}^{2} \cdot \mathrm{V}^{-1} \cdot \mathrm{s}^{-1}$. 研究表明在 CPDT 的 4 号位 烷基官能化和材料纯度对窄带隙聚合物材料的光伏性 能有着关键影响, 为富勒烯太阳能电池领域的研究提供 了一个新的研究方向.

2012 年, Jen 课题组 ${ }^{[51]}$ 研究合成了窄带隙聚合物 PCPDTFBT(图 5). 通过在 BT 单元上引入氟原子改变分 子形态从而提升器件性能, 研究结果表明由 PCPDTFBT:PC 71 BM 混合制备的富勒烯太阳能电池性能 优异, 其 $V_{\mathrm{OC}}$ 为 $0.75 \mathrm{~V}, J_{\mathrm{SC}}$ 为 $15.0 \mathrm{~mA} \cdot \mathrm{cm}^{-2}, F F$ 为 $49 \%$, $\mathrm{PCE}$ 为 $5.51 \%$. 同年 Horie 课题组 ${ }^{[52]}$ 制备了基于 CPDT 单元和 BT 单元的窄带隙低聚物和聚合物 CPDTDBT(图 $5)$, 控制 CPDT 单元与 BT 单元的聚合比例为 $2: 1$. 当 该聚合物与富勒烯质量混合比例为 $1: 1$ 时的器件性能 最佳，其富勒烯太阳能电池的 PCE 为 $2.1 \%$.

2013 年, Jen 课题组 ${ }^{[35]}$ 系统地研究了烷基侧链和氟 取代如何影响 CPDT 基共轭聚合物的光伏性能，他们合 成了一系列具有不同侧链结构和氟取代的 CPDT 基窄带 隙共轭聚合物 EH-FBT、EH-DFBT、DMO-FBT 和 DMO-DFBT(图 5), 当较短的 2-乙基己基( $\mathrm{EH}$ )侧链被较 长的 3,7-二甲基辛基(DMO)侧链取代时，会导致这些聚 合物的电子性质和形态发生显著变化. 这些聚合物的 $\pi-\pi$ 堆积距离会显著影响其 OFET 器件中的迁移率，聚 合物薄膜的 $\pi-\pi$ 堆积距离越短，相应的太阳能电池的迁 移率和填充因数越高. 氟取代基和侧链的调整有助于优 化 $\pi-\pi$ 堆积、聚合物结晶度和溶解度，该系列聚合物的 富勒烯太阳能器件中最高的 PCE 为 $5.5 \%$, 这对新一代 窄带隙聚合物材料进一步开发应用于富勒烯太阳能电 池具有一定的价值.

在太阳能电池中，光敏层的形态可通过调节聚合物 侧链来优化, 大多数的报道研究了侧链的长度和体积, 而很少涉及侧链密度的研究. 对此 2015 年 Maes 课题 组 ${ }^{[53]}$ 设计合成了共聚物 PCPDTQx(2F)(如图 5), 研究了 其侧链密度对器件的影响, 通过调整两部分单体的不同 比例，进而改变了聚合时的侧链密度. 研究发现 PCPDTQx (2F) 窄带隙共聚物上侧链数量对材料性能和 太阳能电池特性的影响很大，其活性层的形态也会受到 
很大影响, 当降低侧链密度时, 可提供更有利的相分离 尺寸。最后基于具有中等侧链密度的共聚物 $\mathrm{P} 12: \mathrm{PC}_{71} \mathrm{BM}$ 的富勒烯太阳能电池器件, 其 PCE 提高到 最大为 $5.63 \%$, 同时研究还发现延长热作用时间后, 去 除部分侧链对器件稳定性也有积极的影响. 因此, 将单 个结构参数 “烷基侧链密度” 用于同时提高富勒烯太阳 能电池的效率和寿命同时也是研究富勒烯太阳能电池 的一个方向.

2020 年 Ayachi 课题组 ${ }^{[54]}$ 利用官能团化的 CPDT 单 元理论研究了共轭程度较高的两个共聚物分子 CPDTOBT 和 CPDTNBT(图 5). 其中 CPDTNBT, 由于其 在桥位置具有两个氰基 $(-\mathrm{C} \equiv \mathrm{N})$ 基团，导致了分子内的 D-A 强烈相互作用, 从而改善了载流子迁移率和 PCE 值, 研究发现基于 CPDTNBT:PCBM 的 PCE 高达 9.5\%. 结果表明通过调整分子设计是改善富勒烯太阳能电池 性能的有效手段之一.
2020 年 Chen 课题组 ${ }^{[55]}$ 设计并制备了一种适合大面 积印刷有机太阳能电池的空穴传输层 (HTL) 材料 PCPDTK $_{0.50} \mathrm{H}_{0.50}$-TT(图 9), 以 PCPDTK ${ }_{0.50} \mathrm{H}_{0.50}$-TT 作为 HTL 的 PM6: $\mathrm{Y}$ 6: $\mathrm{PC}_{71} \mathrm{BM}$ 器件的 PCE 为 $16.3 \%$ (其面积 为 $0.04 \mathrm{~cm}^{2}$ ). 当线棒涂层 PCPDTK $\mathrm{PC}_{0.50} \mathrm{H}_{0.50}$-TT 作为空穴 传输层而制备面积为 $1.0 \mathrm{~cm}^{2}$ 的器件时, 其 PCE 高达 $10.2 \%$. 考虑到大面积打印的优势和可观的器件光电转 换效率, $\mathrm{PCPDTK}_{0.50} \mathrm{H}_{0.50}$ - TT 被认为是有机太阳能电池 工业生产潜在的空穴传输层材料.

\subsubsection{CPDT 在非富勒烯太阳能电池中的应用}

CPDT 在富勒烯太阳能电池中的应用十分广泛，同 样, CPDT 在非富勒烯太阳能电池中的应用也有着非常 重要的地位，其可以构建多种非富勒烯受体应用于太阳 能电池. 而非富勒烯受体也以其吸收范围广、合成简易、 稳定性好等优点也受到了研究者的青睐. 2018 年 Zeng 课题组 ${ }^{[56]}$ 研究合成了基于供电子核心 CPDT 的 2 个小

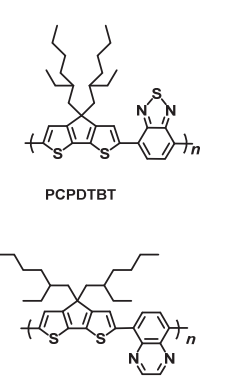

PCPDT-Q
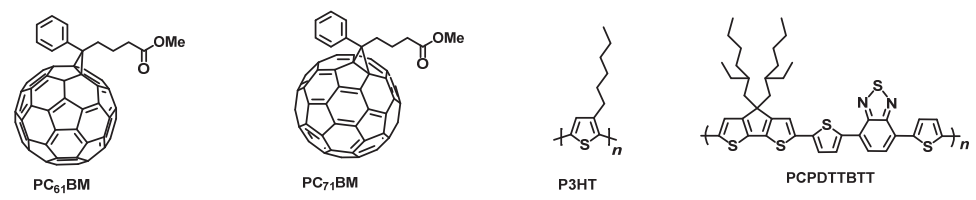

P3HT
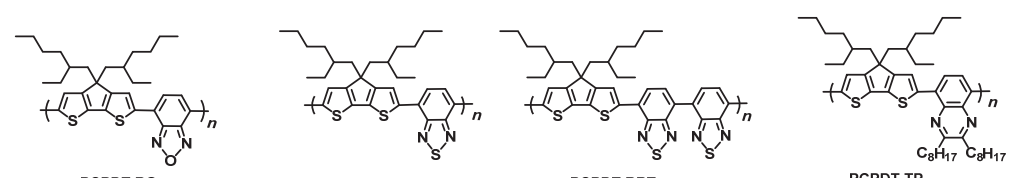

PCPDT-TP

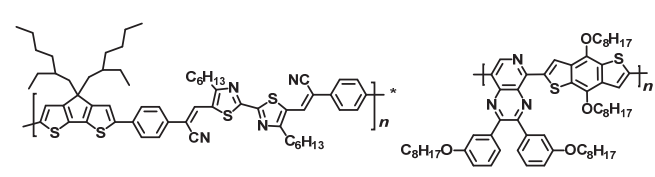

P6

P7

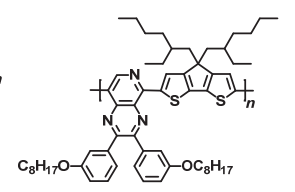

P8
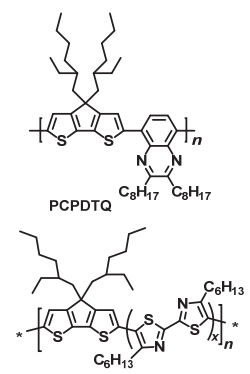

$x=1 \mathrm{P} 1$
$x=2 \mathrm{P} 2$
$x=3 \mathrm{P} 3$

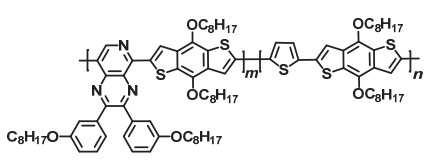

P9

PehCDT-TZ

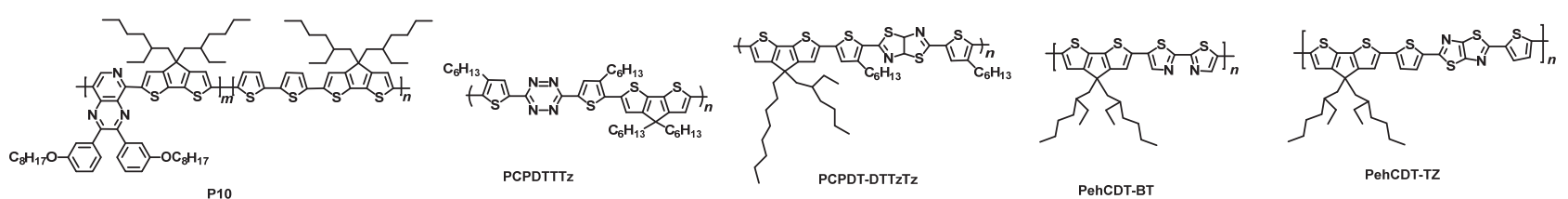

PCPDT-DTTZTZ

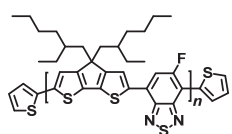

$R^{1}=\overbrace{}^{2}$

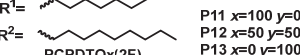

EH-FBT

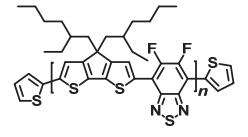

EH-DFBT

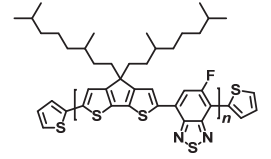

DMO-FBT

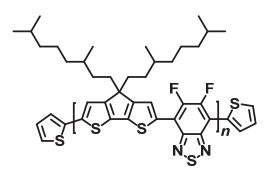

DMO-DFBT

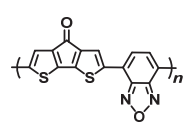

CPDTOBT

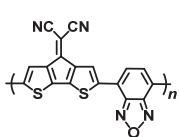

CPDTNBT

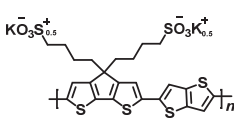

PCPDTK $_{0.50} \mathrm{H}_{0.50} \mathrm{TT}$

图 $5 \mathrm{CPDT}$ 衍生物在富勒烯太阳能电池中的应用的结构示意图

Figure 5 Schematic diagram of the application of CPDT derivatives in fullerene solar cells 
分子受体 $1 \mathrm{CIC}$ 和 $2 \mathrm{CIC}$ (如图 6), 并将其应用于聚合物太 阳能电池. 研究结果表明相对于 1 CIC, 2CIC 具有较窄 的光学带隙, 较强的近红外吸收, 较高的 HOMO 和 LUMO 能量水平, 以及更高的电子迁移率. $2 \mathrm{CIC}$ 与聚合 物 PTB7-Th(图 6)混合制成的非富勒烯太阳能电池器件 也得到了较为优良的性能, 其 $V_{\mathrm{OC}}$ 为 $0.75 \mathrm{~V}, J_{\mathrm{SC}}$ 为 10.97 $\mathrm{mA} \cdot \mathrm{cm}^{-2}, F F$ 为 $43.00 \%$, PCE 为 $3.53 \%$.

2020 年 Bo 课题组 ${ }^{[57]}$ 合成了三种可应用于非富勒烯 太阳能电池的非共价的稠环电子受体材料 FOC6-IC, FOC6-FIC 和 FOC2C6-2FIC(图 6), 三个受体分子主要由 苯将两个 CPDT 连接, 通过微调苯基上的取代基可以改 变器件的性能. 分子结构分析表明, 分子的主链可以通 过形成分子内非共价相互作用而被平面化, 即这些受体 分子可以通过 $\pi-\pi$ 堆积和中心亚苯基单元与端基之间的 静电相互作用以 $0.33 \sim 0.34 \mathrm{~nm}$ 的距离紧密堆积在固态 中. 最终得到基于 PBDB-T(图 6):FOC2C6-2FIC 的非富 勒烯太阳能电池的 $\mathrm{PCE}$ 为 $12.36 \%$, 相对较基于 PBDB-T:FOC6-FIC 非富勒烯太阳能电池 (PCE 为 12.08\%)和基于 PBDB-T:FOC6-IC 非富勒烯太阳能电池 (PCE 为 $10.80 \%$ ) 的性能更好, 该研究结果表明分子间非 共价相互作用在受体分子间的堆积、电荷输运和光伏性 能中有着至关重要的作用.

2020 年 Lee 课题组 ${ }^{[58}$ 通过改变两个 CPDT 单元间 连接的受体进行结构微调, 成功合成了三种 A-D-A'-D-A 型稠环电子受体, 即 BTCPDT、BTCPDTO4 和 BTCPDTF(图 6). 研究结果表明基于 PBDB-T:BTCPDTO4 的非富勒烯太阳能电池的 PCE 最 高达到了 $11.85 \%$. 基于 PBDB-T:BTCPDT 和 PBDBT:BTCPDTF 的非富勒烯太阳能电池的 PCE 相对 较差, 分别为 $7.22 \%$ 和 $7.32 \%$. 这些研究也证明了将具 有短烷基链的供电子取代基插入到 A-D-A'-D-A 型稠环 电子受体中是一种既简便又有效的策略, 同时又可以提 高光伏性能, 最终能够更深入地了解结构与性能之间的 相互影响关系, 为稠环电子受体的研究提供了一定的研 究方向.

同年, Bo 课题组 ${ }^{[59]}$ 同样通过微调 CPDT 单元之间连 接的苯取代基, 设计并合成了四个稠环电子受体, 即 $p$-DOC6-2F, o-DOC6-2F, o-DOC8-2F 和 $o$-DOC2C6$2 \mathrm{~F}$ (如图 6). 在这四个分子中, $p$-DOC6-2F 具有 $\mathrm{S}$ 形构 型、 $C_{2 h}$ 对称性, 且偶极矩较小, 而其他三个呈现 $\mathrm{U}$ 形构 型、 $C_{2 v}$ 对称性, 偶极矩较大. 同时 $C_{2 v}$ 对称分子比相应 的 $C_{2 h}$ 对称分子具有更好的溶解性. 与具有 $C_{2 h}$ 对称的 $p$-DOC6-2F 相比, 具有 $C_{2 v}$ 对称的 $o-\mathrm{DOC}$ 分子受体的吸 收出现了蓝移现象. 以 PBDB-T(具有匹配的能级)作为 供体, 研究了这些受体的光伏性能. 结果发现 PBDB-T: $p$-DOC6-2F 的混合膜表现出大规模的相分离, 这样不良的形态会导致有机太阳能电池器件的性能变 差, 其 $\mathrm{PCE}$ 仅为 $9.23 \%, V_{\mathrm{OC}}$ 为 $0.81 \mathrm{~V}$. 与 $\mathrm{PBDB}-\mathrm{T}$ : $p$-DOC6-2F 的混合膜不同, PBDB-T:o-DOC6-2F 的混合
膜仅呈现出适当的相分离，进而基于 PBDB-T: $o$-DOC6-2F 的器件表现出最佳性能, 其 PCE 为 $11.87 \%$, $V_{\mathrm{OC}}$ 为 $0.89 \mathrm{~V}$. 同时延长或支化烷氧基侧链会略微降低 光伏性能，因此基于 PBDB-T:o-DOC8-2F 的非富勒烯太 阳能电池的 PCE 为 $11.23 \%$, 基于 PBDB-T: $o-\mathrm{DOC} 2 \mathrm{C} 6-2 \mathrm{~F}$ 的非富勒烯太阳能电池的 PCE 为 $10.80 \%$. 结果表明，苯基被取代位点的不同会影响分子的构象， 从而显著影响其在共混膜中的聚集行为，从而证实了分 子对称性是影响器件性能的重要参数, 也为开发基于 CPDT 单元的稠环电子受体提供参考.

基于 CPDT 衍生物与富勒烯受体或非富勒烯受体的 器件处于被持续研究的状态, 但是基于 CPDT 衍生物与 非富勒烯和富勒烯受体的器件领域的研究很少被提及. 对此 2018 年, Chen 课题组 ${ }^{[60]}$ 合成了小分子受体 HC-PCIC(图 6), 将其与非富勒烯受体 PBDB-TF 和富勒 烯受体 $\mathrm{PC}_{71} \mathrm{BM}$ 共同组成了三元有机太阳能电池, 最终 取得了优异的器件性能, $V_{\mathrm{OC}}$ 为 $0.89 \mathrm{~V}, J_{\mathrm{SC}}$ 为 19.29 $\mathrm{mA} \cdot \mathrm{cm}^{-2}, F F$ 为 $70.18 \%, \mathrm{PCE}$ 为 $12.36 \%$.

在此之后, 2021 年 Bo 课题组 ${ }^{[61]}$ 设计并合成了两种 以 $\mathrm{PC}_{71} \mathrm{BM}$ 为横向连接物, $\mathrm{CPDT}$ 为供体基团的非稠环 受体 $\mathrm{PC}_{71} \mathrm{BM}-\mathrm{C} 6$ 和 $\mathrm{PC}_{71} \mathrm{BM}-\mathrm{C} 10$ (图 6). 随着富勒烯基团 的加入, 成功抑制了 $\mathrm{PC}_{71} \mathrm{BM}-\mathrm{C} 6$ 和 $\mathrm{PC}_{71} \mathrm{BM}-\mathrm{C} 10$ 在 A-D-A 骨架中的分子间聚集. 基于三受体的器件均表现 出相当低的非辐射电压损耗，约为 $0.22 \sim 0.24 \mathrm{eV}$, 且新 型混合受体器件的所有光伏性能参数都得到了全面增 强. 另外基于 $\mathrm{PC}_{71} \mathrm{BM}-\mathrm{C} 10$ 的器件实现了 $13.55 \%$ 的 $\mathrm{PCE}, V_{\mathrm{OC}}$ 为 $0.87 \mathrm{~V}, J_{\mathrm{SC}}$ 为 $21.30 \mathrm{~mA} \cdot \mathrm{cm}^{-2}, F F$ 为 $72.66 \%$.

大多数非富勒烯受体具有较大的稠环主链, 通常需 要繁琐的多步合成, 因此不适用于商业应用. 一种替代 策略是开发非稠环的非富勒烯受体, 它在光电特性和固 态微结构方面具有合成简单和易于调节的特点. 2020 年 Huang 课题组 ${ }^{[62]}$ 采用 A-D-A'-D-A 框架, 设计并合成了 两个非稠环非富勒烯受体 BTCIC 和 BTCIC-4Cl(图 6). 在这项工作中, BTCIC 和 BTCIC-4Cl 均具有相同的缺电 子 BTH 中心核 $\mathrm{A}^{\prime}, \mathrm{CPDT}$ 单元用作其中的供电子单元 $\mathrm{D}$, 但具有不同的吸电子单元 A. 通过微调 A 单元结构 来进行光学特性、能级结构和分子结晶度等的调节. 此 外, 将 BTCIC 和 BTCIC-4Cl 分别与聚合物供体 PBDB-T 和 PBDB-T-2Cl 混合, 制备得到非富勒烯太阳能电池器 件分别得到了 $9.3 \%$ 和 $10.5 \%$ 的最高光电转换效率. 这些 结果证明了 A-D-A'-D-A 型非稠环非富勒烯受体具有制 备高性能非富勒烯太阳能电池的巨大潜力, 非稠环非富 勒烯受体的进一步开发也将变得更加有意义.

2020 年 Bo 课题组 ${ }^{[63]}$ 以 CPDT 单元为桥, 设计并合 成了两个稠合噻吩基 PDI 二聚体 CDT-TFP 和 C8X-TFP(图 6). 该课题组还模拟出了两个 PDI 单位桥 接一个 CPDT 单位的分子, 与 CDT-PDI 相比, CDT-TFP 和 C8X-TFP 中 PDI 单元的平面构象和共面 $\pi$ - $\pi$ 有序堆 积更有助于提高电子迁移率. 同时研究了作为非富勒烯 


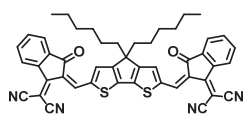

$1 \mathrm{CIC}$

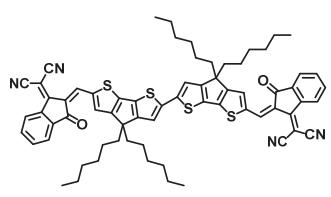

2CIC

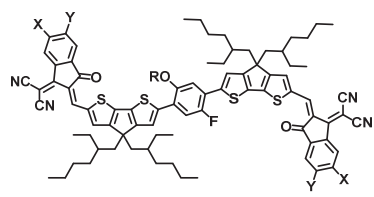

$\begin{array}{ll}\text { FOC6-IC: } & X=Y=H, R=h e x y 1 \\ \text { FOC6-FIC: } & X=H, Y=F \text { or } X=F, Y=H, R=h e x y 1\end{array}$

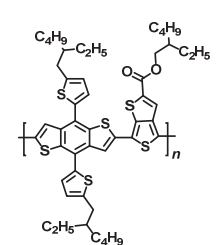

PTB7-Th

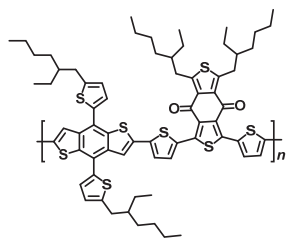

PBDB-T

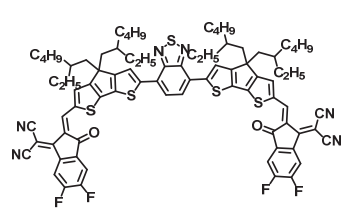

BTCPDT

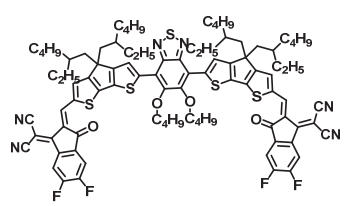

BTCPDTO4

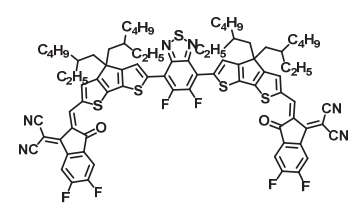

BTCPDTF

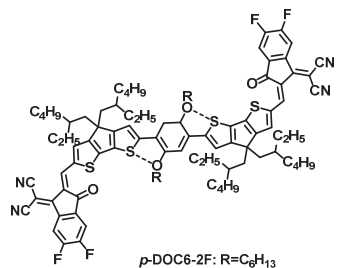

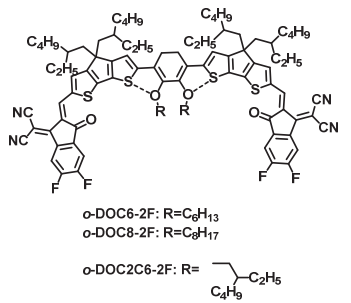

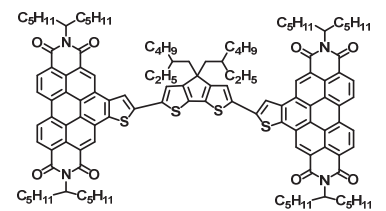

C8X-TFP
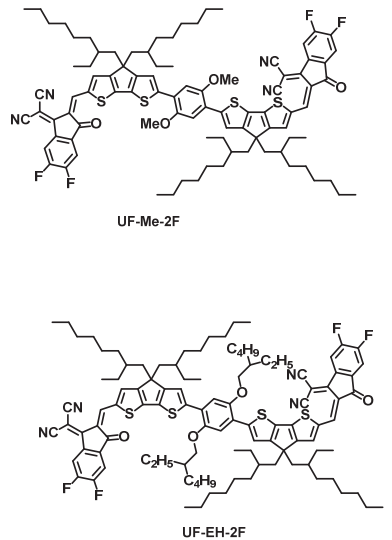
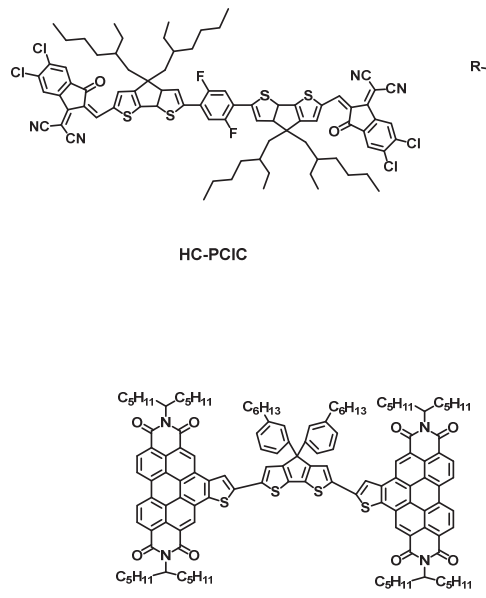

CDT-TFP
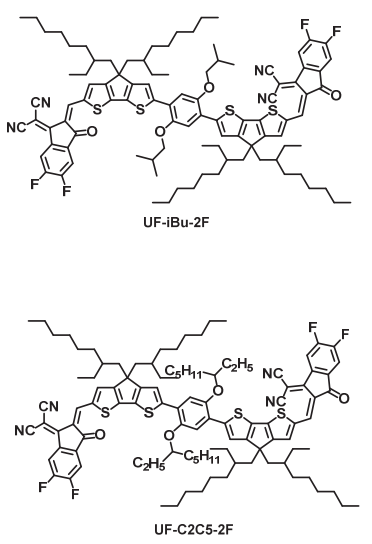
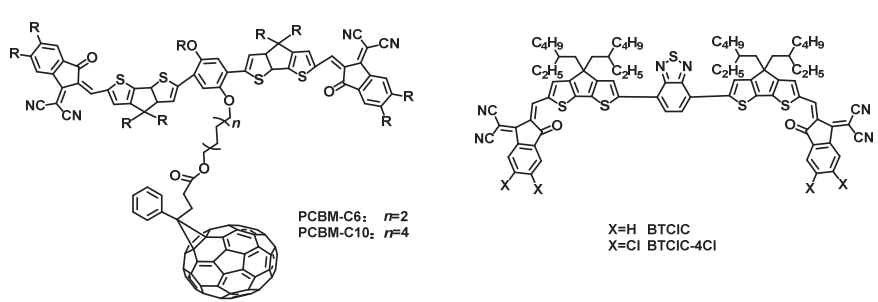

$x=n$ BTCIC
$X=C 1$

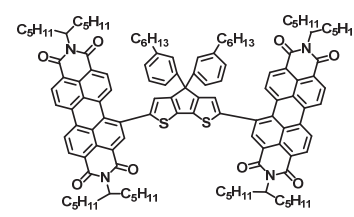

CDT-PDI
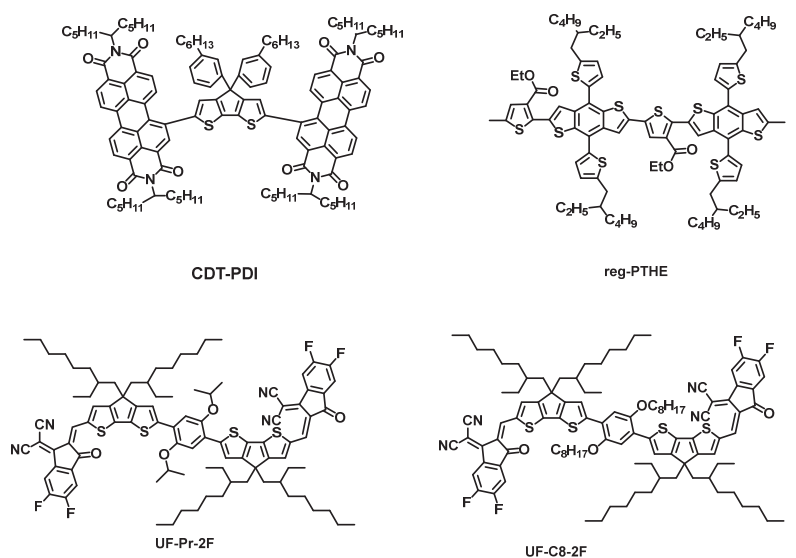

图 6 CPDT 衍生物在非富勒烯太阳能电池中的应用的结构示意图

Figure 6 Schematic diagram of the application of CPDT derivatives in non-fullerene solar cells

电子受体的 CDT-TFP、C8X-TFP 和作为电子给体的 CDT-PDI 的光伏性能, CDT-TFP 的高 LUMO 能级、强吸 收、良好的平面性和良好的共混膜形态提供了更高的 $V_{\mathrm{OC}} 、 J_{\mathrm{SC}}$ 和 $F F$. 基于 reg-PThE(图 6):CDT-TFP 的器件显 示出 $8.36 \%$ 的最佳 $\mathrm{PCE}, V_{\mathrm{OC}}$ 为 $1.10 \mathrm{~V}, J_{\mathrm{SC}}$ 为 12.43
$\mathrm{mA} \cdot \mathrm{cm}^{-2}, F F$ 为 $61.4 \%$; 基于 reg-PThE:C $8 X-T F P$ 的器件 可以实现 $5.21 \%$ 的 $\mathrm{PCE}, V_{\mathrm{OC}}$ 为 $1.09 \mathrm{~V}, J_{\mathrm{SC}}$ 为 9.99 $\mathrm{mA} \cdot \mathrm{cm}^{-2}$ 和 $F F$ 为 $47.7 \%$; 然而基于 reg-PThE:CDT-PDI 的器件 $\mathrm{PCE}$ 仅为 $2.59 \%, V_{\mathrm{OC}}$ 为 $0.92 \mathrm{~V}, J_{\mathrm{SC}}$ 为 6.82 $\mathrm{mA} \cdot \mathrm{cm}^{-2}, F F$ 为 $41.5 \%$. 结果表明, 含有平面 PDI 单元的 
非富勒烯电子受体可以获得优异的光伏性能, 这对研究 基于 PDI 的非富勒烯受体材料具有重要意义.

2020 年 Chen 课题组 ${ }^{[31]}$ 设计合成了 6 个 A-D-A 型受 体分子 UF-Me-2F, UF-iBu-2F, UF-Pr-2F, UF-C8-2F, UF-EH-2F 和 UF-C2C5-2F(如图 7). 其中 CPDT 作为供 体 $\mathrm{D}$, 通过在两个 CPDT 单元之间的苯基上进行微调, 该课题组合成了具有相似主链结构的 A-D-A 型小分子 受体系列. 研究结果表明通过线性调节化学结构可以进 一步改变设备效率和稳定性. 通过控制分子聚集和有序 的堆积形态之间的平衡, 可以得到高效和稳定的分子, 因此具有最佳长度和侧链位阻的 UF-EH-2F 在其相应的 器件中 “有效态” 和 “稳定态” 几乎重叠, 获得了优越 的形态, 稳定性达到了最佳, PCE 也达到了 $13.56 \%$. 通 过微调有机太阳能电池活性材料的化学结构, 可以同时 实现高效和高稳定性所需的形态, 在高性能分子应用上 微调化学结构的策略, 可能推进具有高性能和高稳定性 的太阳能电池的商业化生产.

2020 年 $\mathrm{Li}$ 课题组 ${ }^{[64]}$ 为解决高效近红外电子受体材 料合成复杂的问题, 设计并合成了一种简单的近红外电 子受体 W1(图 8). 它的最大吸收波长高达 $1000 \mathrm{~nm}$. 基 于 PTB7-Th:W1 的有机光电探测器(OPD)有着快速的时 间响应以及 $1.70 \times 10^{-11} \mathrm{~W} \cdot \mathrm{cm}^{-2}$ 的超低光强度检测等优 点. W1 与 PTB7-Th 聚合物混合制备的非富勒烯太阳能 电池在 $\mathrm{AM} 1.5$ 光谱作为测试电池效率的标准光源下, 其 $\mathrm{PCE}$ 为 $9.22 \%, V_{\mathrm{OC}}$ 为 $0.65 \mathrm{~V}, J_{\mathrm{SC}}$ 为 $22.10 \mathrm{~mA} \cdot \mathrm{cm}^{-2}, F F$ 为 $64 \%$.

\section{2 在染料敏化太阳能电池(DSCs)中的应用}

染料敏化太阳能电池是一种通过模仿光合作用原 理而研制出的新型太阳能电池, 通过模拟利用太阳能进 行光合作用, 进而可以将太阳能转化为电能. 在染料敏 化太阳能电池中, CPDT 单元在光敏剂中应用也非常广 泛. 2011 年, Wang 课题组 ${ }^{[4]}$ 研究合成了基于 CPDT 单元 的小分子 C229(图 7), 制备了一种基于 C229 和三(1,10菲咯啉)钴电解质的无碘染料敏化太阳能电池, 其 PCE 达到了 $9.4 \%$, 这在当时是最高的光电转换效率.

同年 Grätzel 课题组 ${ }^{[65]}$ 通过分子工程策略, 引入 CPDT, 合成了分子 Y123(图 7). 其光谱响应扩展到了红 外区域, 增强了吸收太阳光的能力. 基于 Y123 分子制 备的新型染料敏化电池其 PCE 高达 9.6\%. 同年该课题 组 ${ }^{[66]}$ 也设计合成了一种新型 D- $\pi-A$ 染料 C220(图 7), C220 可用于固态敏化异质结太阳能电池, 与 Z907(图 7) 分子相比, C220 具有更高的电荷产生、收集效率和摩尔 吸收系数. 另外有机 D- $\pi-\mathrm{A}$ 染料 C220 在 AM 1.5 光谱作 为测试电池效率的标准光源下显示出的 PCE 达到 $6.08 \%$, 在当时刷新了这种类型的敏化异质结光伏器件 性能的新纪录.

2012 年 Han 课题组 ${ }^{[67]}$ 通过在 D-A-A 型中引入强吸 电子的 CDT, 成功合成了新的近红外染料敏化剂 HIQ1、
HIQ2 和 HIQ3(如图 7). 通过调节给体部分的给电子能 力, 吸收光谱达到了 $900 \mathrm{~nm}$. 其中用 HIQ3 敏化的染料 敏化太阳能电池的 PCE 达 1.31\%. 值得注意的是，入射 单色光子-电子转化效率(IPCE)光谱显示其具有从可见 光区到近红外区 $1100 \mathrm{~nm}$ 的宽响应. 这些结果表明含有 CDT 单元的 D-A-A 结构的化合物具有作为近红外增感 剂的巨大潜力, 可以用于制备高效染料敏化太阳能电 池.

2014 年 Wang 课题组 ${ }^{[68]}$ 将苯并噻二唑-环戊并二噻 吩(BTH-CPDT)部分作为 $\pi$ 桥联引入到染料 D1(图 7)中, 合成了一种新的 D-A- $\pi-A$ 光敏剂 D2 (图 7), 发现在长波 长区域的光吸收大大增强. 该染料具有高达 $800 \mathrm{~nm}$ 的 宽可见光吸收, 在 AM 1.5 光谱作为测试电池效率的标 准光源, 使用基于 $\left[\mathrm{Co}(\mathrm{bpy})_{3}\right]^{2+/ 3+}$ 电解质的染料敏化太 阳能电池已实现超过 9\%的 PCE.

在染料敏化太阳能电池中，基于苯并三氮唑基敏化 剂WS-5(图 7)的太阳能电池显示出了相对较高的开路电 压, 也获得了较高的 $\operatorname{PCE}(8.02 \%)$, 但 WS-5 在溶液和二 氧化钛薄膜上的吸收带都非常窄, 有限的光电流值严重 限制了光伏性能. 对此 2014 年 Zhu 课题组 ${ }^{[69]}$ 通过巧妙 的分子设计合成了更有效的敏化剂，将辛基和甲基取代 的 CPDT 单元引入到基于吲哚啉的 D-A- $\pi$-A 敏化剂的骨 架中作为 $\pi$ 桥单元，替换已知敏化剂 WS-5 中的共轭噻 吩桥单元, 分别合成了染料Ws-39 和 Ws-43(图 7). CPDT 链上的辛基链可以提供双重保护，产生有效的屏蔽效 应，以延缓电荷复合. 在 $\mathrm{AM} 1.5$ 光谱作为测试电池效 率的标准光源, 基于辛基取代的 WS-39 的染料敏化太 阳能电池的 $J_{\mathrm{SC}}$ 为 $16.61 \mathrm{~mA} \cdot \mathrm{cm}^{-2}, V_{\mathrm{OC}}$ 为 $0.770 \mathrm{~V}, F F$ 为 $71 \%, \mathrm{PCE}$ 为 $9.07 \%$. 这一工作为实现高功率转换效率的 敏化剂提供了合理的分子策略, 为增加光吸收的研究提 供了方向.

Zhu 课题组 ${ }^{[70]} 2015$ 年又设计了一种 D-A- $\pi$-A 型喹 喔啉有机敏化剂 IQ21(图 7), 通过引入 CPDT 高共轭结 构单元作为 $\pi$ 桥, 代替了传统的噻吩单元, 实现了 $66600 \mathrm{~L} \cdot \mathrm{mol}^{-1} \cdot \mathrm{cm}^{-1}$ 高分子消光系数, 并延伸了光响应 波长. IQ21 和共吸染料 $\mathrm{S}_{2}$ (图 5)两种染料的分子匹配良 好, 且共吸收染料 $\mathrm{S}_{2}$ 可以补偿 $\mathrm{Q} 21$ 的固有缺陷，制备的 染料敏化太阳能电池最佳 PCE 为 $10.41 \%, J_{\mathrm{SC}}$ 为 19.8 $\mathrm{mA} \cdot \mathrm{cm}^{-2}, V_{\mathrm{OC}}$ 为 $0.731 \mathrm{~V}, F F$ 为 $72 \%$. 这项研究表明具有 匹配分子大小、形状和取向的共增敏染料可以提高染料 敏化太阳能电池的效率.

2016 年 Robertson 课题组 ${ }^{[71]}$ 通过简单的交叉偶联法 合成了一系列具有㲵基丙烯酸基团的“无供体”染料 CPDT-1、CPDT-2 和 CPDT-3(图 7). 在所有类型的染料 敏化太阳能电池中, CPDT 基的加入都能使 $J_{\mathrm{SC}} 、 V_{\mathrm{OC}}$ 和 PCE 有所增加. 同时, CPDT-3 在这一系列电池中表现出 最高的光电转换效率 $\left(6.7 \%\right.$ 的 $\mathrm{I}^{-} / \mathrm{I}^{3-}$ 基电池， $7.3 \%$ 的 $\left[\mathrm{Co}(\mathrm{bpy})_{3}\right]^{2+/ 3}$ 基电池和 $3.9 \%$ 的固态电池). CPDT 单元 
的高消光系数和宽吸收光谱为其设计高效无供体染料 敏化太阳能电池提供了基础.

\section{3 在钙钛矿太阳能电池中的应用}

钙钛矿太阳能电池属于第三代太阳能电池, 具有高 电荷载流子迁移率和高消光系数等优点, 得到了广大科 学家的重视与研究. 在钙钛矿太阳能电池中空穴传输材 料(HTMs)在实现高性能方面起着至关重要的作用, 在 这其中, CPDT 由于其特有的性质也发挥着一定的作用.
在 2019 年 Sun 课题组 ${ }^{[72]}$ 设计合成了三种可应用于钻钛 矿电池新的 D-A-D 型空穴传输材料, 分别为 $\mathrm{YC}-1$, YC-2 和 YC-3(图 8). 该材料以 4-二氰甲基-4H-环戊二烯 $\left[2,1-b ; 3,4-b^{\prime}\right]$ 二噻吩(DiCNCPDT)核作为电子受体，两个 双(对甲氧基苯基氨基苯基)基团作为电子供体. 研究结 果表明, YC-1 在钙钛矿空穴传输界面上表现出更高效 的空穴迁移特性, 这是由于 YC-1 薄膜在钙钛矿层上覆 盖均匀致密，从而提高了填充因子和开路电压. 基于

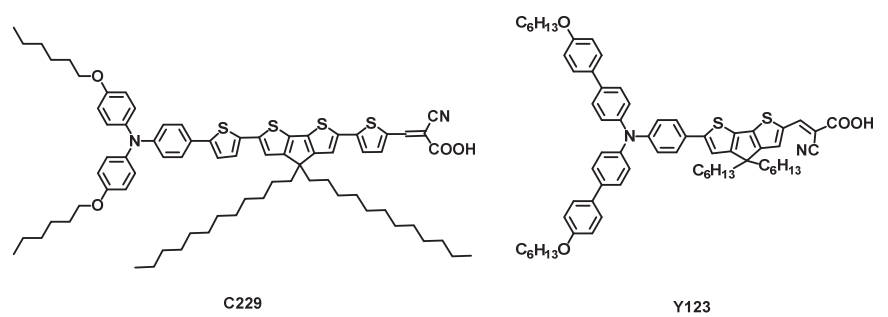

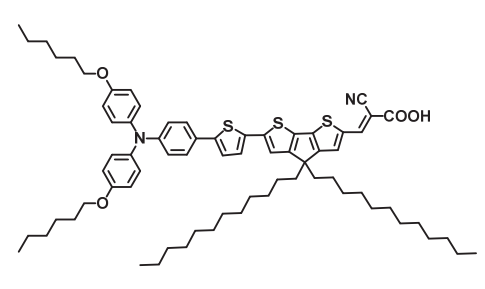

$\mathrm{C} 220$

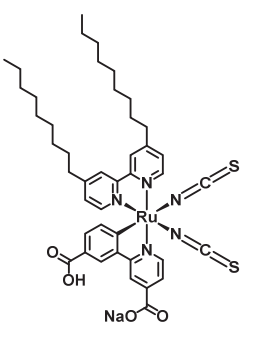

$z 907$

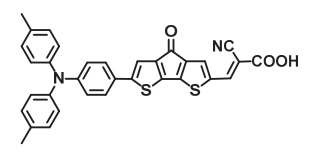

HIQ1

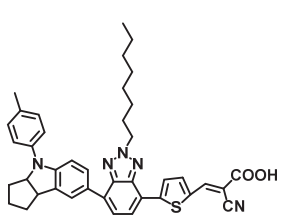

WS-5

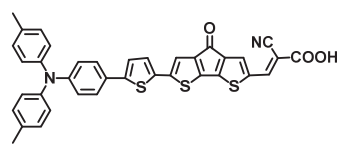

HIQ2

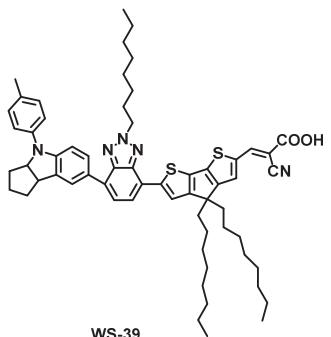

ws-39

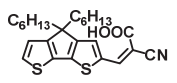

CPDT-1

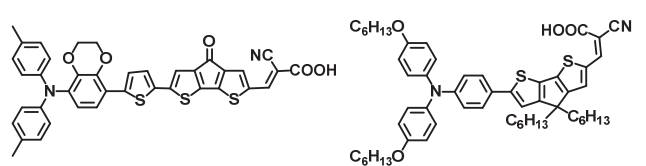

$D_{1}$

HIQ3

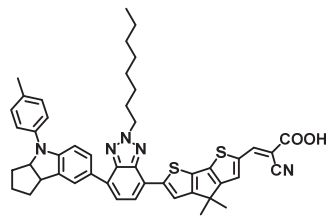

Ws-43

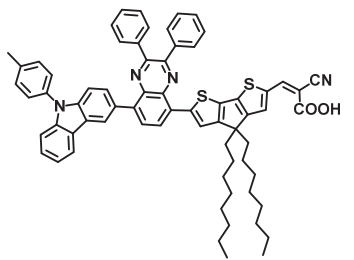

$1 Q_{21}$
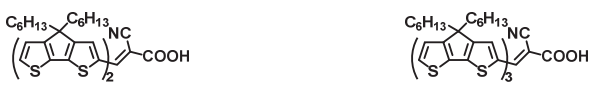

CPDT-2

CPDT-3

图 $7 \mathrm{CPDT}$ 衍生物在染料敏化太阳能电池中的应用的结构示意图

Figure 7 Schematic diagram of the application of CPDT derivatives in dye-sensitized solar cells
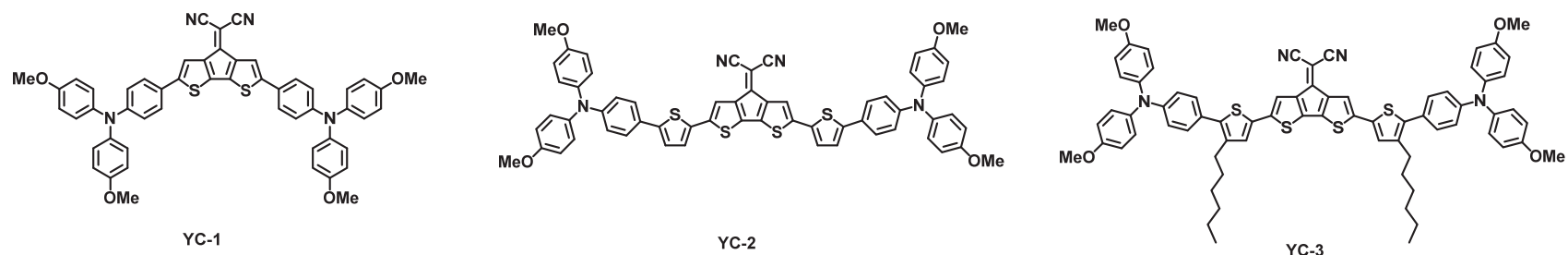

图 $8 \mathrm{CPDT}$ 衍生物在钙钛矿太阳能电池中的应用的结构示意图

Figure 8 Schematic diagram of the application of CPDT derivatives in perovskite solar cells 
YC-1 的钙钛矿电池表现出高功率转换效率 PCE 为 $18.03 \%$, 拥有较好的稳定性, 在相对湿度 $30 \%$ 的条件下 放置超过 $500 \mathrm{~h}$ 仍有 $85 \%$ 的初始效率保留. 这些优良的 性能参数表明: 基于 CPDT 单元的双氧亚甲基衍生物在 钲钛矿太阳能电池中是一类高效稳定的空穴传输材料.

\section{4 在其他领域的应用}

CPDT 及其衍生物除了在太阳能电池和有机受体等 领域的应用非常广泛外, 在其他光电材料领域也有着非 常重要的应用，包括：场效体晶体管、有机热电、 $\mathrm{Li}$ 离 子电池、有机闪存等方面.

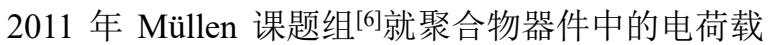
流子迁移率比较低的问题, 通过改变分子量策略设计合 成了分子 P14 和 P15(图 9). 经过测试发现随着数均分子 量的增加, P14 和 P15 的薄膜在场效应晶体管中的空穴 迁移率稳定上升, 在场效应晶体管(FETs)中的空穴迁移 率最高达到了 $3.3 \mathrm{~cm}^{2} \cdot \mathrm{V}^{-1} \cdot \mathrm{s}^{-1}$. 结果表明聚合物分子量 的提高对于改善薄膜结晶度可能具有潜在作用，从而提 高聚合物场效应晶体管空穴迁移率.

2017 年 Bazan 课题组 ${ }^{[73]}$ 设计并合成了三种环戊并 二噻吩-二氟亚苯基共聚物, 根据三种共聚物在亚苯基 结构单元上的氟排列不同，将其命名为 $\mathrm{PhF} 2,3 、 \mathrm{PhF} 2,5$

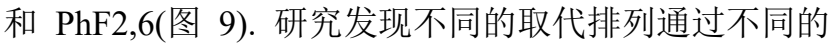
非键相互作用影响主链二级结构, PhF2,5 和 PhF2,6 相对 于 $\mathrm{PhF} 2,3$ 呈现出更多的线性主链, 这反过来也会影响 纳米自组装和聚合物链排列. 对于线性更好的主链, 实 现了电荷载流子迁移率的更大改善, 在三种聚合物中, PhF2,6 获得了最高的平均场效应空穴迁移率 (5.1 $\left.\mathrm{cm}^{2} \bullet \mathrm{V}^{-1} \cdot \mathrm{s}^{-1}\right)$, 这表明具有线性形状的聚合物可能更有
利于实现有序的排列，从而获得更高的迁移率.

在 2012 年 Neher 课题组 ${ }^{[74]}$ 引入了一种新型的氟化 共聚物 F-PCPDTBT(图 9), 与窄带隙聚合物 PCPDTBT 相比, 与 $\mathrm{PC}_{71} \mathrm{BM}$ 共混的太阳能电池显示出更高的 $\mathrm{PCE}$. 由于氟化降低了聚合物的 $\mathrm{HOMO}$ 值, 导致 $V_{\mathrm{OC}}$ 远远超过 $0.7 \mathrm{~V}$, 氟化 PCPDTBT 与 $\mathrm{PC}_{71} \mathrm{BM}$ 的共混物的性能很大 程度上取决于自由载流子产生的场依赖性, 并且与非氟 化聚合物的共混物相比，电场依赖性要弱得多. 对于这 些优化的混合体系, 其作为器件应用于聚合物的串联太 阳能电池中可以实现 $J_{\mathrm{SC}}$ 为 $14 \mathrm{~mA} \cdot \mathrm{cm}^{-2}, V_{\mathrm{OC}}$ 为 $0.74 \mathrm{~V}$, $F F$ 为 $58 \%$, 同时其 PCE 达到了 $6.16 \%$.

2016 年 $\mathrm{Ng}$ 课题组 ${ }^{[7]}$ 采用一种新的供体-受体聚合物 CPDT-alt-BSe(图 9)和 $\mathrm{PC}_{71} \mathrm{BM}$ 制备了体异质结光电二极 管. 该光电二极管在 $1 \mu \mathrm{m}$ 波长下可实现高达 $10^{12} \mathrm{Jones}$ 的探测率，线性动态范围为 $86 \mathrm{~dB}$. 另外通过对暗电流 和光谱响应的温度依赖性的分析, 发现当温度从 $44{ }^{\circ} \mathrm{C}$ 降低到 $-12{ }^{\circ} \mathrm{C}$ 时，探测灵敏度提高了 2.8 倍，与基于无 机的器件相比, 变化相对较小.

锂离子电池 $(\mathrm{LiB})$ 在智能手机、平板电脑和个人电脑 等便携式电子设备以及电动汽车的能量存储方面有着 广阔的应用前景，而在锂离子电池的大规模生产中，共 轭聚合物粘合剂有着非常重要的地位. 在 2017 年 Horie 课题组 ${ }^{[75]}$ 通过简单的直接芳基化聚合然后皇化的方法 合成了一系列共轭聚合物粘合剂 P[CPDT(EH)-B]、 P[CPDT(EH)-TPA]和 P[CPDT(EG)-TPA](图 9). 这些聚 合物由 CPDT 单元和对苯二甲酸二甲酯或对苯二甲酸单 元组成，可以将聚合物与硅纳米粒子混合，制成用于锂 离子电池的阳极电极. 与㿝化前的聚合物相比，含有皇

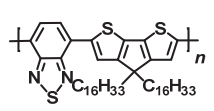

P14
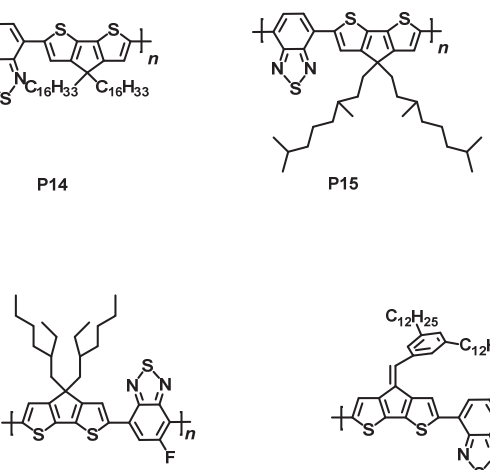

F-PCPDTBT

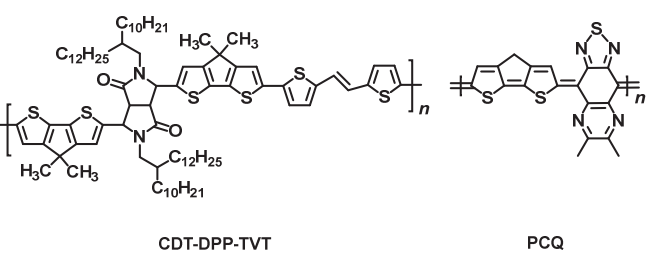

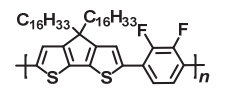

PhF2,3

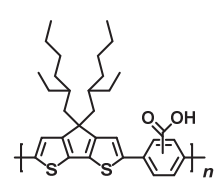

$\operatorname{P}[\mathrm{CPDT}(\mathrm{EH})-\mathrm{B}]$

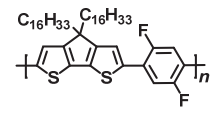

PhF2,5

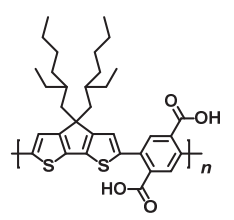

P[CPDT(EH)-TPA]

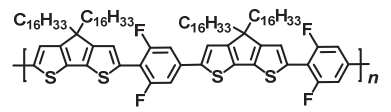

PhF2,6

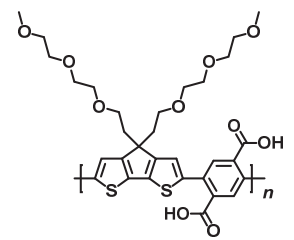

P[CPDT(EG)-TPA]

图 $9 \mathrm{CPDT}$ 衍生物在其他领域的应用的结构示意图

Figure 9 Schematic diagram of the application of CPDT derivatives in other fields 
化聚合物电极的电池在第二次循环中具有高达 2500 $\mathrm{mA} \cdot \mathrm{h} \cdot \mathrm{g}^{-1}$ 的比容量和更高的稳定性. 尽管电池循环寿命 目前在实际应用中表现一般, 但导电聚合物粘合剂硅纳 米粒子系统将碳质材料替换成了石墨作为阳极材料, 锂 电池的稳定性可以通过系统优化得到提高. 该策略可应 用于锂离子电池中各种无机电极材料的其他共轭聚合 物粘合剂的设计和合成, 该合成方法也有可能在高性能 聚合物粘合剂的合成中得到广泛的运用.

2020 年 Chung 课题组 ${ }^{[76]}$ 合成了一系列基于 CPDT 单元和二酮吡咯并吡咯(DPP)单元的新型供体-受体共 聚物 CDT-DPP-TVT(图 9). 测试结果表明该共聚物在 $10^{5} \mathrm{~s}$ 内有着出色的偏置应力稳定性, 即可通过在 Cytop 层之间嵌入金纳米粒子作为电荷存储位点来制造浮栅 晶体管. 由该材料制备的存储器件显示出具有大于 $10^{4}$ 高开关电流比的双稳态电流状态, 且每个状态的保留时 间均在 1 年以上. 此外, 重复的写入-读取-擦除-读取测 试结果表明该器件具有良好的耐受性和稳定性, CDT-DPP-TVT 的内部稳定性使该共聚物在有机闪存领 域有很大的发展空间.

有机热电因其显著的优势, 包括可室温发电、具有 生物相容性的皮肤附着、穿戴应用等引起了广泛的关注. 2018 年, Azoulay 课题组 ${ }^{[77]}$ 通过 Still 偶联合成了共轭聚 合物 PCQ(图 9), 其由交替的环戊并二噻吩 CPDT 单元 和噻二唑并喹啉骨架组成. 该骨架在没有掺杂剂的情况 下显示出窄带隙、开壳电子基态、固有电导率 $\left(\sigma \approx 10^{-3}\right.$ $\left.\mathrm{S} \cdot \mathrm{cm}^{-1}\right)$ 和大的塞贝克系数 $\left(S>1000 \mu \mathrm{V} \cdot \mathrm{K}^{-1}\right)$. 添加特制 的开壳掺杂剂可显著提高 $\sigma$, 并允许系统地控制热电特 性, 从而使优化功率因数大于 $10 \mu \mathrm{W} \cdot \mathrm{m}^{-1} \cdot \mathrm{K}^{-2}$, 这是非 传统共轭聚合物热电系统报告的最大值之一. 这种含自 由基大分子与开壳小分子掺杂剂的结合开辟了一条新 途径, 通过这种途径可以控制电荷传输并改善下一代聚 合物热电系统的性能.

在有机材料中, 自掺杂共轭聚电解质 $(\mathrm{CPEs})$ 是一类 很有前途的导电有机材料, 被认为是有机热电材料的潜 在候选材料. 然而, 由于其低电导率 $(\sigma)$ 导致的低功率因 数一直是热电学中基于热电堆的主要缺点. 因此, 2020 年 Baran 课题组 ${ }^{[78]}$ 报告了通过使用 $\mathrm{H}_{2} \mathrm{SO}_{4}$ 溶液的后处理 来提高自掺杂共轭聚电解质 PCPDTBT- $\mathrm{SO}_{3} \mathrm{~K}$ (图 9)的热 电性能, 后处理使 $\sigma$ 增加了 2 个数量级, 这源于 $\mathrm{H}_{2} \mathrm{SO}_{4}$ 诱导的掺杂伴随着电荷载流子浓度的显著增加. 因此, 室温下的功率因数为 $3.0 \mu \mathrm{W} \cdot \mathrm{m}^{-1} \cdot \mathrm{K}^{-2}$. 此外, 使用这种 高导电性的硫酸掺杂共轭聚电解质可以开发柔性热电 发电机, 在重复的机械弯曲应力下允许持久发电. 该研 究为下一代有机热电器件开发提供了研究方向. 这种后 处理方式有望成为提高热电性能的一种策略.

同年 Woo 课题组 ${ }^{[79]}$ 制备了一种新的 $\mathrm{sp}^{2}$ 杂化烯烃双 (烷基磺酰基) 亚甲基取代的 $\mathrm{P}$ 型聚合物 PCPDTSBT-A(图 9), 它具有低极性聚乙二醇(OEG)侧
链，与具有正常烷基侧链的 PCPDTSBT(图 9)对应物进 行比较, 研究了掺杂和形态对电导率和热电性能的影 响. 与带有烷基取代基的 PCPDTSBT 相比, OEG 侧链显 著提高了自掺杂的能力. 具有 OEG 链的 PCPDTSBT-A 的掺杂效率显示出更好的兼容性, 而不破坏原始聚合物 膜的结晶有序性. 与聚对苯二甲酸丁二醇酯相比, OEG 侧链取代和顺序溶液掺杂方法的协同效应使聚对苯二 甲酸丁二醇酯具有更高的电导率和功率因数. 这项研究 提供了一个很好的例子, 说明分子结构和掺杂方法之间 的重要关系, 以及它们对掺杂、电导率和热电聚合物的 热电性能的协同作用.

\section{5 总结与展望}

环戊并二噻吩类衍生物的研究从未停止, 其中 CPDT 研究更为广泛且被人们所关注. 它不仅含有刚性 的平面联噻吩结构，还拥有电导率高、带隙窄和可扩展 的 $\pi$ 共轭以及易于在其刚性的噻吩环上引入多种功能基 团等的优点, 这使环戊并二噻吩类衍生物在有机太阳能 电池、有机场效应晶体管、有机发光二极管等领域已显 示出广泛的潜在应用前景, 且在相关领域的研究十分活 跃, 也已经取得了许多重要的研究成果. 今后 CPDT 作 为有机太阳能电池材料的重要构建单元, 研究重点仍需 集中在提高材料的溶解性、电子亲和能和载荷迁移率等 方面，基于聚合物的太阳能电池领域任重而道远. 尽管 如此，我们发现 CPDT 及其衍生物的应用在结构上更多 是线性聚合物或者 “D-A” 型的小分子系列，然而基于 CPDT 大环类结构的报道甚少. 近几年, 我们课题组致 力于芴及类芴类有机纳米格芳烃(ONGA) 分子的研究, 建立了系列葋基梯形格、风车格、缺角格以及 $3 \mathrm{D}$ 格的 合成与应用. 同时在理论与实验方面, 将有机半导体的 格子化策略应用于 CPDT 的设计, 在 CPDT 基风车格以 及梯形格方面实现了合成层面的突破，我们期待未来 CPDT 基格芳烃在有机光电领域有着不一样的光彩与成 就.

综上所述环戊并二噻吩类衍生物作为电子给体单 元在构筑光电材料方面表现出极大的发展潜力和广泛 的潜在应用. 未来, 在有机半导体的空间设计理念指导 下，随着格子化学、多尺度化学以及第四代半导体与柔 性材料等多领域的探索, 环戊并二噻吩类衍生物作为类 芴结构将成为有机半导体格子化的关键构筑合成子单 元，基于环戍并二噻吩类衍生物的风车格、梯形格、缺 角格以及 “井” 字形格等的合成及其在有机纳米聚合物 材料的研究与应用将取得更大的突破，必将有更多的环 戊并二噻吩类有机纳米格芳烃及其聚格在塑料电子领 域得到实际应用, 丰富有机光电材料化学领域的科学内 涵. 


\section{作者简介}

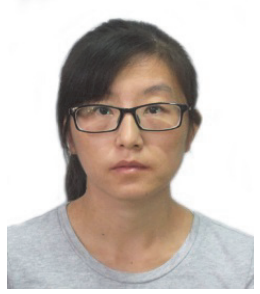

魏颖, 南京邮电大学材料科学与工程学院副教授、硕士生 导师. 2005 至 2009 年就读于吉林化工学院, 获得学士学位. 2009 至 2014 年就读于东北师范大学化学学院, 获得博士学位. 随后加入南京邮电大学信息材料与纳米技术研究院/材料科学 与工程学院. 目前主要研究方向为有机/聚合物的合成及其性 质.

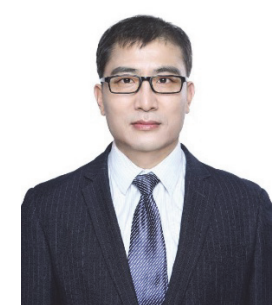

解令海, 南京邮电大学信息材料与纳米技术研究院/材料 科学与工程学院教授、博士生导师, 国家百千万人才工程人选, 享受国务院政府特殊津贴. 2000 年和 2003 年分别获得东北师 范大学学士学位和汕头大学硕士学位. 2003 至 2006 年就读于 复旦大学先进材料研究院, 获得博士学位. 他长期从事有机 智能与第四代半导体研究, 涉及柔性电子、人工化学智能与智 能化学、智能机器人化学家等未来领域的基础研究.

\section{References}

[1] Xie, L.-H.; Yin, C.-R.; Lai, W.-Y.; Fan, Q.-L.; Huang, W. Prog. Polym. Sci. 2012, 37, 1192.

[2] Benincori, T.; Consonni, V.; Gramatica, P.; Pilati, T.; Rizzo, S.; Sannicolò, F.; Todeschini, R.; Zotti, G. Chem. Mater. 2001, 13, 1665.

[3] Wang, Z.; Putta, A.; Mottishaw, J. D.; Wei, Q.; Wang, H.; Sun, H. J. Phys. Chem. C 2013, 117, 16759.

[4] Bai, Y.; Zhang, J.; Zhou, D.; Wang, Y.; Zhang, M.; Wang, P. J. Am. Chem. Soc. 2011, 133, 11442.

[5] Sun, S.; Xu, Y.; Liang, M.; Sun, Z.; Xue, S. Chin. J. Org. Chem. 2011, 31, 511 (in Chinese). (孙思远, 徐英军, 梁茂, 孙喆, 薛松, 有机化学, 2011, 31, 511.)

[6] Tsao, H. N.; Cho, D. M.; Park, I.; Hansen, M. R.; Mavrinskiy, A.; Yoon, D. Y.; Graf, R.; Pisula, W.; Spiess, H. W.; Müllen, K. J. Am. Chem. Soc. 2011, 133, 2605.

[7] Wu, Z.; Yao, W.; London, A. E.; Azoulay, J. D.; Ng, T. N. ACS Appl. Mater. Interfaces 2016, 9, 1654.

[8] Fusalba, F.; Mehdi, N. E.; Breau, L.; Bélanger, D. Chem. Mater. 1999, 11, 2743.

[9] Zotti, G.; Zecchin, S.; Schiavon, G.; Berlin, A. Macromolecules 2001, 34, 3889.

[10] Yang, Y.; Zhao, J.-F.; Liu, R.-R.; Li, J.-W.; Yi, M.-D.; Xie, G.; Xie, L.-H.; Chang, Y.; Yin, C.-R.; Zhou, X.-H.; Zhao, Y.; Qian, Y.; Huang, W. Tetrahedron 2013, 69, 6317.

[11] Kraak, A.; Wiersema, A. K.; Jordens, P.; Wynberg, H. Tetrahedron 1968, 24, 3381.

[12] Roncali, J. Chem. Rev. 1997, 97, 173.

[13] Xie, L.-H. Ph.D. Dissertation, Fudan University, Shanghai, 2006 (in Chinese). (解令海, 博士论文, 复旦大学, 上海, 2006.)

[14] Coppo, P.; Cupertino, D.; Yeates, S. G.; Turner, M. L. J. Mater. Chem. 2002, 12, 2597.

[15] Mierloo, S. V.; Adriaensens, P. J.; Maes, W.; Lutsen, L.; Cleij, T. J.;
Botek, E.; Champagne, B.; Vanderzande, D. J. J. Org. Chem. 2010 , 75,7202 .

[16] Gibson, G. L.; McCormick, T. M.; Seferos, D. S. J. Am. Chem. Soc. 2011, 134, 539

[17] Bijleveld, J.; Shahid, M.; Gilot, J.; Wienk, M.; Janssen, R. $A d v$. Funct. Mater. 2009, 19, 3262.

[18] Zhao, X.; Chaudhry, S. T.; Mei, J. Adv. Heterocycl. Chem. 2017, $121,133$.

[19] Hong, D.-H.; Chen, L.; Kong, Q.-G.; Cao, H. Chinese J. Chem. Phys. 2018, 31, 171 (in Chinese). (洪顶豪, 陈力, 孔庆刚, 曹晖, 化学物理学报, 2018, 31, 171.)

[20] Soci, B. C.; Hwang, I.-W.; Moses, D.; Zhu, Z.; Waller, D.; Gaudiana, R.; Brabec, C. J.; Heeger, A. J. Adv. Funct. Mater. 2007, 17, 632.

[21] Liu, Z.; Bao, Y.; Ling, H.; Hu, H.; Ju, H.; Xie, L.-H.; Bian, L.; Chang, Y.; Yi, M.; Huang, W. J. Polym. Sci., Part A: Polym. Chem. 2016, 54,3140 .

[22] Huang, H.; Pickup, P. G. Chem. Mater. 1999, 11, 1541.

[23] Jordens, P.; Rawson, G.; Wynberg, H. J. Chem. Soc. C 1970, 273.

[24] Xie, L.-H.; Hou, X.-Y.; Tang, C.; Hua, Y.-R.; Wang, R.-J.; Chen, R.-F.; Fan, Q.-L.; Wang, L.-H.; Wei, W.; Peng, B.; Huang, W. Org. Lett. 2006, 8, 1363.

[25] Coppo, P.; Turner, M. J. Mater. Chem. 2005, 15, 1123.

[26] Xie, L.-H.; Hou, X.-Y.; Hua, Y.-R.; Huang, Y.-Q.; Zhao, B.-M.; Liu, F.; Peng, B.; Wei, W.; Huang, W. Org. Lett. 2007, 9, 1619.

[27] Moulé, A. J.; Tsami, A.; Bünnagel, T. W.; Forster, M.; Kronenberg, N. M.; Scharber, M.; Koppe, M.; Morana, M.; Brabec, C. J.; Meerholz, K.; Scherf, U. Chem. Mater. 2008, 20, 4045.

[28] Raju, T. B.; Peddaboodi, G.; Iyer, P. K. RSC Adv. 2014, 4, 37738.

[29] Berlin, A.; Brenna, E.; Pagani, G. A.; Sannicolò, F.; Zotti, G.; Schiavon, G. Synth. Met. 1992, 51, 287.

[30] Fei, Z.; Gao, X.; Smith, J.; Pattanasattayavong, P.; Domingo, E. Stingelin, E. B.; Stingelin, N.; Watkins, S. E.; Anthopoulos, T. D.; Kline, R. J.; Heeney, M. Chem. Mater. 2013, 25, 59.

[31] Chang, M.; Meng, L.; Wang, Y.; Ke, X.; Yi, Y.-Q.-Q.; Zheng, N.; Zheng, W.; Xie, Z.; Zhang, M.; Yi, Y.; Zhang, H.; Wan, X.; Li, C.; Chen, Y. Chem. Mater. 2020, 32, 2593.

[32] Li, K.-C.; Huang, J.-H.; Hsu, Y.-C.; Huang, P.-J.; Chu, C.-W.; Lin, J.-T.; Ho, K.-C.; Wei, K.-H.; Lin, H.-C. Macromolecules 2009, 42, 3681 .

[33] Yuan, M.-C.; Chiu, M.-Y.; Chiang, C.-M.; Wei, K.-H. Macromolecules 2010, 43, 6270.

[34] Jung, I. H.; Yu, J.; Jeong, E.; Kim, J.; Kwon, S.; Kong, H.; Lee, K.; Woo, H. Y.; Shim, H.-K. Chem. Eur. J. 2010, 16, 3743.

[35] Li, Y.; Zou, J.; Yip, H.-L.; Li, C.-Z.; Zhang, Y.; Chueh, C.-C.; Intemann, J.; Xu, Y.; Liang, P.-W.; Chen, Y.; Jen, A. K.-Y. Macromolecules 2013, 46, 5497.

[36] Yang, L.; Mao, J.; Yin, C-Z.; Wu, X-P.; Liu, Y-Y.; Xie, L.-H.; Ran, X.-Q.; Huang, W. Chem. Phys. 2019, 516, 191.

[37] Lin, D.; Wei, Y.; Peng, A.; Zhang, H.; Zhong, C.; Lu, D.; Zhang, H.; Zheng, X.; Yang, L.; Feng, Q.; Xie, L.-H.; Huang, W. Nat. Commun. 2020, 11, 1756 .

[38] Xie, X.; Wei, Y.; Lin, D.; Zhong, C.; Xie, L.-H.; Huang, W. Chin.. J. Chem. 2019, 38, 103.

[39] Zhang, G.; Wei, Y.; Wang, J.; Liu, Y.; Xie, L.-H.; Wang, L.; Ren, B.; Huang, W. Mater. Chem. Front. 2017, 1, 455.

[40] Sun, S.; Ou, C.; Lin, D.; Zuo, Z.; Yan, Y.; Wei, Y.; Liu, Y.; Xie, L.-H.; Huang, W. Tetrahedron 2018, 74, 5833.

[41] Wei, Y.; Feng, Q.; Liu, H.; Wang, X.; Lin, D.; Xie, S.; Yi, M.; Xie, L.-H.; Huang, W. Eur. J. Org. Chem. 2018, 48, 7009.

[42] Tang, L. M.S. Thesis, Nanjing University of Posts and Telecommunications, Nanjing, 2018 (in Chinese). (唐否, 硕士论文, 南京邮电 大学, 南京, 2018.)

[43] Wang, X. M.S. Thesis, Nanjing University of Posts and Telecommunications, Nanjing, 2019 (in Chinese). (汪秀丽，硕士论文，南京邮 电大学, 南京, 2019.)

[44] Lu, L.; Zheng, T.; Wu, Q.; Schneider, A. M.; Zhao, D.; Yu, L. Chem. Rev. 2015, 115, 12666.

[45] Sariciftci, N. S.; Smilowitz, L.; Heeger, A. J.; Wudl, F. A. Science 1992, 258, 1474.

[46] Morita, S.; Zakhidov, A. A.; Yoshino, K. Solid State Commun. 1992, $82,249$.

[47] Yu, G.; Gao, J.; Hummelen, J. C.; Wudl, F.; Heeger, A. J. Science 1995, 270, 1789.

[48] Liu, Z.; Xu, F.; Yan, D. Acta Chim. Sinica 2014, 72, 171 (in Chinese). (刘震, 徐丰, 严大东, 化学学报, 2014, 72, 171.)

[49] Li, Z.; Ding, J.; Song, N.; Lu, J.; Tao, Y. J. Am. Chem. Soc. 2010, 
132,13160 .

[50] Mierloo, S. V.; Hadipour, A.; Spijkman, M.-J.; Brande, N. V.; Ruttens, B.; Kesters, J.; D’Haen, J.; Assche, G. V.; Leeuw, D. M.; Aernouts, T.; Manca, J.; Lutsen, L.; Vanderzande, D. J.; Maes, W. Chem. Mater. 2012, 24, 587.

[51] Zhang, Y.; Zou, J.; Cheuh, C.-C.; Yip, H.-L.; Jen, A. K.-Y. Macromolecules 2012, 45, 5427.

[52] Horie, M.; Kettle, J.; Yu, C.-Y.; Majewski, L. A.; Chang, S.-W.; Kirkpatrick, J.; Tuladhar, S. M.; Nelson, J.; Saunders, B. R.; Turner, M. L. J. Mater. Chem. 2012, 22, 381.

[53] Verstappen, P.; Kesters, J.; D’Olieslaeger, L.; Drijkoningen, J.; Cardinaletti, I.; Vangerven, T.; Bruijnaers, B. J.; Willems, R. E. M.; D’Haen, J.; Manca, J. V.; Lutsen, L.; Vanderzande, D. J. M.; Maes, W. Macromolecules 2015, 48, 3873.

[54] Zaier, R.; Cruz, M. P. D. L.; Puente, F. L. D. L.; Ayachi, S. J. Phys. Chem. Solids 2020, 145, 109532.

[55] Xu, H.; Zou, H.; Zhou, D.; Zeng, G.; Chen, L.; Liao, X.; Chen, Y. ACS Appl. Mater. Interfaces 2020, 12, 52028.

[56] Cao, J.; Liu, S.; Hu, W.; Xu, Y.; Zhou, W.; Zeng, Y.; Yu, J.; Tang, Z. Synth. Met. 2018, 240, 15.

[57] Feng, S.; Li, M.; Tang, N.; Wang, X.; Huang, H.; Ran, G.; Liu, Y.; Xie, Z.; Zhang, W.; Bo, Z. ACS Appl. Mater. Interfaces 2020, 12, 4638.

[58] Yoon, N.; Jeong, J.-Y.; Oh, S.; Song, C. E.; Ken, L. H.; Shin, W. S.; Lee, J.-C.; Moon, S.-J.; Lee, S. K. ACS Appl. Energ. Mater. 2020, 3, 12327.

[59] Hou, R.; Li, M.; Ma, X.; Huang, H.; Lu, H.; Jia, Q.; Liu, Y.; Xu, X.; Li, H.-B.; Bo, Z. ACS Appl. Mater. Interfaces 2020, 12, 46220.

[60] Zhan, L.; Li, S.; Zhang, S.; Chen, X.; Lu, T.-K.; Lu, X.; Shi, M.; Li, C.-Z.; Chen, H. ACS Appl. Mater. Interfaces 2018, 10, 42444.

[61] Zhou, Y.; Li, M.; Shen, S.; Wang, J.; Zheng, R.; Lu, H.; Liu, Y.; Ma, Z.; Song, J.; Bo, Z. ACS Appl. Mater. Interfaces 2021, 13, 1603.

[62] Pang, S.; Zhou, X.; Zhang, S.; Tang, H.; Dhakal, S.; Gu, X.; Duan, C.; Huang, F.; Cao, Y. ACS Appl. Mater. Interfaces 2020, 12, 16531.

[63] Liu, J.; Lu, H.; Liu, Y.; Zhang, J.; Li, C.; Xu, X.; Bo, Z. ACS Appl. Mater. Interfaces 2020, 12, 10746.
[64] Wen, T.-J.; Wang, D.; Tao, L.; Xiao, Y.; Tao, Y.-D.; Li, Y.; Lu, X.; Fang, Y.; Li, C.-Z.; Chen, H.; Yang, D. ACS Appl. Mater. Interfaces 2020, 12, 39515.

[65] Tsao, H. N.; Yi, C.; Moehl, T.; Yum, J.-H.; Zakeeruddin, S. M.; Nazeeruddin, M. K.; Grätzel, M. ChemSusChem 2011, 4, 591.

[66] Cai, N.; Moon, S.-J.; Cevey-Ha, L.; Moehl, T.; Humphry-Baker, R.; Wang, P.; Zakeeruddin, S. M.; Grätzel, M. Nano Lett. 2011, 11 1452 .

[67] Qin, C.; Islam, A.; Han, L. Dyes and Pigments 2012, 94, 553.

[68] Wang, X.; Yang, J.; Yu, H.; Li, F.; Fan, L.; Sun, W.; Liu, Y.; Koh, Z.; Pan, J.; Yim, W.-L.; Yan, L.; Wang, Q. Chem. Commun. 2014, 50, 3965.

[69] Chai, Q.; Li, W.; Wu, Y.; Pei, K.; Liu, J.; Geng, Z.; Tian, H.; Zhu, W. ACS Appl. Mater. Interfaces 2014, 6, 14621.

[70] Pei, K.; Wu, Y.; Li, H.; Geng, Z.; Tian, H.; Zhu, W.-H. ACS Appl. Mater. Interfaces 2015, 7, 5296.

[71] Hu, Y.; Abate, A.; Cao, Y.; Ivaturi, A.; Zakeeruddin, S. M.; Graetzel, M.; Robertson, N. J. Phys. Chem. C 2016, 120, 15027.

[72] Lin, Y.-D.; Abate, S. Y.; Chung, H.-C.; Liau, K.-L.; Tao, Y.-T.; Chow, T. J.; Sun, S.-S. ACS Appl. Energ. Mater. 2019, 2, 7070.

[73] Wang, M.; Ford, M. J.; Zhou, C.; Seifrid, M.; Nguyen, T.-Q.; Bazan, G. C. J. Am. Chem. Soc. 2017, 139, 17624.

[74] Albrecht, S.; Janietz, S.; Schindler, W.; Frisch, J.; Kurpiers, J.; Kniepert, J.; Inal, S.; Pingel, P.; Fostiropoulos, K.; Koch, N.; Neher, D. J. Am. Chem. Soc. 2012, 134, 14932.

[75] Yao, C.-F.; Wang, K.-L.; Huang, H.-K.; Lin, Y.-J.; Lee, Y.-Y.; Yu, C.-W.; Tsai, C.-J.; Horie, M. Macromolecules 2017, 50, 6924.

[76] Jeon, S.; Cheng, S.; Yu, S. H.; Kwon, S.-k.; Chung, D. S.; Jeong, Y. J.; Kim, Y.-H. ACS Appl. Mater. Interfaces 2020, 12, 2743.

[77] Joo, Y.; Huang, L.; Eedugurala, N.; London, A.; Kumar, A.; Wong, B. M.; Boudouris, B.; Azoulay, J. D. Macromolecules 2018, 51, 3886.

[78] Kee, S.; Haque, M. A.; Lee, Y.; Nguyen, T. L.; Rosasvillalva, D.; Troughton, J.; Alshareef, H. N.; Woo, H. Y.; Baran, D. ACS Appl. Energ. Mater. 2020, 12, 5743

[79] Tripathi, A.; Ko, Y.; Kim, M.; Lee, Y.; Lee, S.; Park, J.; Kwon, Y.-W.; Kwak, J.; Woo, H. Y. Macromolecules 2020, 53, 7063.

(Cheng, B.) 